\title{
Article \\ Microstructural Transitions during Powder Metallurgical Processing of Solute Stabilized Nanostructured Tungsten Alloys
}

\author{
Nicholas Olynik ${ }^{1}$, Bin Cheng ${ }^{1}$, David J. Sprouster ${ }^{1}$ (D) Chad M. Parish $^{2}$ and Jason R. Trelewicz ${ }^{1,3, *(1)}$ \\ 1 Department of Materials Science and Chemical Engineering, Stony Brook University, Stony Brook, NY 11794, \\ USA; nicholas.olynik@stonybrook.edu (N.O.); bin.cheng@stonybrook.edu (B.C.); \\ david.sprouster@stonybrook.edu (D.J.S.) \\ 2 Materials Science and Technology Division, Oak Ridge National Laboratory, Oak Ridge, TN 37831, USA; \\ parishcm@ornl.gov \\ 3 Institute for Advanced Computational Science, Stony Brook University, Stony Brook, NY 11794, USA \\ * Correspondence: jason.trelewicz@stonybrook.edu
}

Citation: Olynik, N.; Cheng, B.; Sprouster, D.J.; Parish, C.M.; Trelewicz, J.R. Microstructural Transitions during Powder Metallurgical Processing of Solute Stabilized Nanostructured Tungsten Alloys. Metals 2022, 12, 159. https:// doi.org/10.3390/met12010159

Academic Editor: Jordi Sort Viñas

Received: 16 November 2021

Accepted: 11 January 2022

Published: 15 January 2022

Publisher's Note: MDPI stays neutral with regard to jurisdictional claims in published maps and institutional affiliations.

Copyright: (c) 2022 by the authors. Licensee MDPI, Basel, Switzerland. This article is an open access article distributed under the terms and conditions of the Creative Commons Attribution (CC BY) license (https:/ / creativecommons.org/licenses/by/ $4.0 /)$.

\begin{abstract}
Exploiting grain boundary engineering in the design of alloys for extreme environments provides a promising pathway for enhancing performance relative to coarse-grained counterparts. Due to its attractive properties as a plasma facing material for fusion devices, tungsten presents an opportunity to exploit this approach in addressing the significant materials challenges imposed by the fusion environment. Here, we employ a ternary alloy design approach for stabilizing $\mathrm{W}$ against recrystallization and grain growth while simultaneously enhancing its manufacturability through powder metallurgical processing. Mechanical alloying and grain refinement in W-10 at.\% Ti- $(10,20)$ at.\% $\mathrm{Cr}$ alloys are accomplished through high-energy ball milling with transitions in the microstructure mapped as a function of milling time. We demonstrate the multi-modal nature of the resulting nanocrystalline grain structure and its stability up to $1300{ }^{\circ} \mathrm{C}$ with the coarser grain size population correlated to transitions in crystallographic texture that result from the preferred slip systems in BCC W. Field-assisted sintering is employed to consolidate the alloy powders into bulk samples, which, due to the deliberately designed compositional features, are shown to retain ultrafine grain structures despite the presence of minor carbides formed during sintering due to carbon impurities in the ball-milled powders.
\end{abstract}

Keywords: tungsten; nanocrystalline alloys; high-energy ball milling; spark plasma sintering; fusion materials; grain boundary engineering

\section{Introduction}

Grain size refinement and the introduction of compositional complexities are two key tools in designing unique microstructures with nanoscale features that can enhance material properties relative to classical engineering materials. In nanocrystalline metals, the deliberate introduction of solute that has an energetic preference to segregate to grain boundaries - often referred to as grain boundary doping (including deliberate alloying and impurity segregation) - has emerged as an effective means of stabilizing nanocrystalline materials against thermal [1-5], mechanical [6-8], and irradiation instabilities [9-11]. Because these materials contain a high-volume fraction of grain boundaries with excess free energy, they are not easily processed via traditional thermomechanical processing routes and instead rely on far-from-equilibrium processes such as physical vapor deposition (PVD), electrodeposition, high-energy ball milling, and severe plastic deformation (SPD) [12]. While all these techniques can produce the desired grain boundary-rich microstructures, deposition-based processes are limited in their scalability, while it is difficult to achieve simultaneous alloying and grain size refinement via SPD. High-energy ball milling represents a class of powder metallurgical processing that is inherently scalable and, due to the high deformation energy, can mechanically alloy combinations of powders while 
simultaneously refining the grain size to produce single-phase nanocrystalline alloys [13]. This process is particularly convenient for achieving non-equilibrium microstructures in body-centered cubic (BCC) metals, which are not easily produced with nanocrystalline grain sizes through other SPD processes due to the lack of a close-packed slip system facilitating high deformation strains.

High-energy ball milling relies on repeated high-energy collisions between a powder charge and milling media to repeatedly deform, cold weld, and fracture the powder particles [14]. In powder mixtures containing different materials, the high deformation energies lead to solid-state mixing, referred to as mechanical alloying, while concomitantly refining the microstructural length scales (i.e., the grain size) of the powder and its particle size distribution [13]. This technique is easily scalable to a bulk material manufacturing process by increasing the milling jar size, volume of the powder charge, and number/size of the chosen milling media. Planetary ball milling represents one of the more common high-energy ball milling processes designed specifically to achieve energies that produce mechanical alloying and microstructure refinement. Relative to a shaker mill, the planetary mill also minimizes contamination due to degradation and wear of the milling media through the introduction of multiple rotation axes [13]. Microstructures produced via planetary ball milling ultimately depend on the characteristics of the particle impact (e.g., energy, frequency, etc.), which are dictated by the processing parameters, including mediato-powder ratio, milling speed, atmosphere, temperature, total effective time (sometimes including intermittent off time measured by an effective duty cycle), and the selected process control agent (PCA) [15-18]. In addition to the high-volume fraction of grain boundaries intrinsic to the nanocrystalline state produced via high-energy ball milling, processed powders also contain an appreciable number of other defects including point defects, stacking faults, dislocations, and shear bands [19].

Due to its particularly attractive properties as a plasma-facing material (PFM), tungsten (W) materials development has sought to address the challenging needs of future fusion reactors [20]. Concerns over extended exposure of coarse-grained $\mathrm{W}$ to the anticipated conditions of the fusion environment, including microstructural stability [21], resilience against plasma-induced surface damage [22], and degradation of bulk properties due to neutron irradiation [23], has motivated the study of advanced W-based materials [2,24-28] with grain size refinement to the nanocrystalline regime representing a promising pathway for improving the performance characteristics of W [29-31]. Nanocrystalline W powders have been produced via high-energy ball milling and exhibited grain sizes in the range of $5-25 \mathrm{~nm}[17,18]$; however, the far-from-equilibrium state occupied by nominally pure nanocrystalline $\mathrm{W}$ renders it thermally unstable at relevant PFM temperatures [1]. Alloying has been leveraged to suppress the instability of nanostructured materials by exploiting the unique thermodynamics of the nanocrystalline state [32-35]. On this basis, $\mathrm{W}-20$ at.\% Ti powders synthesized through high-energy ball milling and aged for one week at $1100{ }^{\circ} \mathrm{C}$ exhibited a stable grain size of $\sim 20 \mathrm{~nm}$ [36] while an elemental nanocrystalline $\mathrm{W}$ powder with an identical starting grain size coarsened by over an order of magnitude to a grain size of $600 \mathrm{~nm}$. The deliberately designed nanocrystalline alloy thus demonstrated a markedly enhanced thermal stability, which recently has been shown to be complemented by stability against irradiation-induced grain growth [9].

The consolidation of nanocrystalline powders into bulk materials has relied extensively on field-assisted sintering technology (FAST) to circumvent the coarsening kinetics by rapidly heating a powder charge using an electric current passed simultaneously through a graphite die and the powder during the simultaneous application of an external pressure $[37,38]$. Through closed-loop feedback control, the current is manipulated to tailor the temperature profile in the powder (though gradients are expected that depend on the thermal and electrical conductivity of the powder charge [39]), which, when combined with the applied force, promote rapid densification of the powder feedstock into a bulk material over time that limits the degree of coarsening experienced by the microstructure [40]. Sintering of elemental W via FAST has been performed to near total density (i.e., 99.9\%), at temperatures 
as low as $1700^{\circ} \mathrm{C}$ through the use of two-step sintering [41] while single-step sintering often produces lower densities despite driving the process to higher temperatures [42-44]. Given the intrinsic thermal instabilities of nanocrystalline $\mathrm{W}$ combined with recrystallization temperatures ranging from $1100-1300{ }^{\circ} \mathrm{C}$ (depending on the $\mathrm{W}$ grade) [45-48], FAST is even limited in its ability to retain nano grain sizes in $\mathrm{W}$ despite the short sintering times [49-52]. The addition of second phase components such as $\mathrm{WC}, \mathrm{NiFe}$, and $\mathrm{NiCu}$ have driven the lower bound of this temperature range down to $\sim 1200{ }^{\circ} \mathrm{C}$ for full density compacts, albeit often containing a second lower temperature phase [37,44]. Nanostructure stabilization via grain boundary doping as demonstrated in the W-20 at.\% Ti alloy powder discussed above opens up the possibility of producing bulk nanocrystalline alloys from nano-engineered powders. Indeed, a recent study on a W-15 at.\% $\mathrm{Cr}$ alloy has demonstrated that grain sizes approaching the nanocrystalline regime can be retained through sintering of ball-milled powders with significantly enhanced densification rates relative to a coarse-grained $\mathrm{W}-\mathrm{Cr}$ alloy of nominally equivalent composition [53]. The improved stability and sinter-ability were attributed to a synergistic alloying effect involving $\mathrm{Cr}$ segregation to grain boundaries and nano-phase separation of Cr-rich nanoclusters, where the latter provided enhanced diffusion pathways for accelerated interparticle necking and densification [53,54].

Recognizing the unique benefits of synergistic doping in the nanocrystalline state, we propose a ternary alloy design strategy for $\mathrm{W}$ that exploits Ti for the suppression of thermal instabilities (i.e., recrystallization, grain growth, and phase separation) and $\mathrm{Cr}$ for promoting rapid densification during sintering while retaining the nanocrystalline grain structure. Here, we map microstructural evolution and corresponding transitions in two W-Ti-Cr alloys during high-energy ball milling employing complementary $\mathrm{X}$-ray diffraction and transmission electron microscopy analysis. Focus is placed on understanding grain size and texture evolution as a function of milling time and their implications for the morphological evolution of the milled powders. Thermal stability is evaluated at temperatures up to $1300{ }^{\circ} \mathrm{C}$ on powders milled to a minimum achievable grain size with a minor fraction of retained $\mathrm{Cr}$ BCC phase. Finally, these powders are employed in the production of bulk alloys through FAST with microstructural evolution through sintering analyzed relative to unalloyed, coarse-grained $\mathrm{W}$ powders consolidated under identical conditions. We show that the deliberately designed $\mathrm{W}$ alloys are thermally stable above the typical recrystallization temperatures for $\mathrm{W}$ and consolidate to the near-full density at markedly reduced sintering temperatures relative to $\mathrm{W}$.

\section{Materials and Methods}

The configurational space for the design of ternary nanostructured alloys is vast [55] and must consider co-segregation behavior and its potential impact on alloy stabilization relative to its binary counterpart. To that end, we focused our high-energy ball milling and FAST investigation on two W-rich alloy concentrations selected based on prior studies of the binary $\mathrm{W}-\mathrm{Ti}$ and $\mathrm{W}-\mathrm{Cr}$ systems. As described in the introduction, the addition of up to 20 at. \% Ti and 15 at. $\%$ Cr produced stable nanocrystalline configurations in W [36,54]. We thus selected a ternary alloy concentration of W-10 at.\% Ti-20 at.\% Cr (denoted herein W-10Ti-20Cr) for the milling study, which maintains the total alloy concentration below the range to be considered a multi-principal element alloy while balancing the addition of $\mathrm{Ti}$ and $\mathrm{Cr}$ for thermal stability [1] and sinter-ability [53]. Additional work is underway on modeling energy minimized alloy configurations in the ternary W-Ti-Cr system to capture induced/competing segregation effects and their implications for stability. While alloy compositions will be refined based on these results, our purpose in this study is to map out the processing and stability space in select $\mathrm{W}-\mathrm{Ti}-\mathrm{Cr}$ alloys, which is consistent with relying on prior published models for selecting the $\mathrm{W}-10 \mathrm{Ti}-20 \mathrm{Cr}$ alloy. Based on the large fraction of retained $\mathrm{Cr}$ during the milling of this alloy, the solute concentration was adjusted to W-10 at.\% Ti-10 at.\% Cr (denoted herein W-10Ti-10Cr) for the production of powders used in FAST consolidation. 
High-energy ball milling was conducted on blended powders (Alfa Aesar, Haverhill, MA, USA) of W (12 $\mu \mathrm{m}, 99 \%), \mathrm{Ti}(<44 \mu \mathrm{m}, 99 \%)$, and $\mathrm{Cr}(<10 \mu \mathrm{m}, 99.2)$ under an argon atmosphere using a Retsch PM 100 planetary ball mill (Retsch, Haan, Germany). A 50 mL tungsten carbide (WC) jar was employed with $5 \mathrm{~mm}$ diameter WC balls as the grinding media. Holding the ball-to-powder ratio constant at 5:1, a total of 75 WC balls were loaded into the jar for each run. A stearic acid PCA was used with a concentration of $1 \%$ by mass, which facilitated milling at $550 \mathrm{rpm}$ for times of 1, 4, 6, 8, and $12 \mathrm{~h}$ with little powder agglomeration following removal from the milling jar. This milling procedure was applied to the $\mathrm{W}-10 \mathrm{Ti}-20 \mathrm{Cr}$ powder blend with structural characteristics mapped as a function of milling time. Based on these results, $\mathrm{W}-10 \mathrm{Ti}-10 \mathrm{Cr}$ powder blend was milled for $12 \mathrm{~h}$ with thermal stability assessed following heat treatment at $1000^{\circ} \mathrm{C}, 1150{ }^{\circ} \mathrm{C}$, and $1300{ }^{\circ} \mathrm{C}$ for $1 \mathrm{~h}$ under a reducing atmosphere using Ar-5\%H in an MTI GSL-1600X tube furnace (MTI Corporation, Richmond, VA, USA). Sintering of the as-milled W-10Ti-10Cr powder was accomplished using a LABOX-3010KF Field Assisted Sintering System (SinterLand, Niigata, Japan). A cylindrical graphite die, $13 \mathrm{~mm}$ in diameter and lined internally with graphite foil, was loaded with $5 \mathrm{~g}$ of powder and placed into the sintering machine under a vacuum (pressure of $<10 \mathrm{~Pa}$ ) where it was subsequently compressed between the platens to a pressure of $50 \mathrm{MPa}$. The loaded dies were then heated at a rate of $100^{\circ} \mathrm{C} / \mathrm{min}$ to two different temperatures- $1200{ }^{\circ} \mathrm{C}$ and $1400{ }^{\circ} \mathrm{C}$ - where they held for 5 min before cooling. Following removal from the sintering machine, the sintered samples were sandblasted to remove the graphite foil and any additional surface contamination. The nominally pure $\mathrm{W}$ powder used as the feedstock in the milling of the $\mathrm{W}-\mathrm{Ti}-\mathrm{Cr}$ alloys was also sintered in the as-received state following the same sintering procedures and served as a reference for the sintered nanostructure alloy. Density of the sintered samples was determined using the Archimedes method [56] with relative densities determined with respect to theoretical alloy density calculations.

Particle size analysis employed wet dispersion laser diffraction using a MicrotracS3500 particle size analyzer (Microtrac, Haan, Germany). C concentration was quantified using combustion infrared absorption following ASTM E 1941-10 in a LECO CS744 carbon/sulfur analyzer (LECO, St. Joseph, MO, USA). Powder morphology was imaged as a function of milling time in a JEOL 7600F scanning electron microscope (SEM) (JEOL, Tokyo, Japan) at the Center for Functional Nanomaterials. Powder samples were mounted on $C$ tape and imaged using an accelerating voltage of $5 \mathrm{kV}$. Quantitative analysis of grain size and phase fractions was accomplished via X-ray diffraction (XRD) using the X-ray Powder Diffraction beamline at the National Synchrotron Light Source-II [57]. Powders were mounted in Kapton capillaries with patterns collected in transmission mode using $63.61 \mathrm{keV}$ X-rays (wavelength $0.1949 \AA$ ) and background correction through subtracting a diffraction pattern from an empty Kapton capillary. XRD of the sintered samples was also conducted at the beamline in transmission mode on sections extracted from the center of the sintered disks and subsequently thinned to $100 \mu \mathrm{m}$. A single XRD pattern acquired on a bulk sample generally encompassed an area of $500 \mu \mathrm{m}^{2}$ with 4-5 independent patterns recorded over a total area of $\sim 1 \mathrm{~mm}^{2}$. Texture effects in the powders were instead probed in reflection mode (Bragg-Brentano geometry) using an Ultima III system (Rigaku, Tokyo, Japan) with a Cu K $\alpha$ source (wavelength of $1.541 \AA$ ) employing a scan range of $20-100^{\circ}$, step size of $0.1^{\circ}$, and scan time of $5 \mathrm{~s}$ per step. Rietveld refinements were performed using the MAUD software package (version 2.99, Trento, Italy) [58] with an instrumental broadening function determined from a NIST $\mathrm{LaB}_{6}$ standard. Grain size measurements were confirmed through scanning transmission electron microscopy (STEM) in a Thermo Talos F200X TEM/STEM at $200 \mathrm{keV}$ (Thermo Fisher Scientific, Waltham, MA, USA). Powders were dispersed onto an aluminum stub covered with conductive $C$ tape, followed by standard FIB lift out in an FEI Quanta3D (Thermo Fisher Scientific, Waltham, MA, USA). These instruments are housed at the Oak Ridge National Laboratory Low Activation Materials Development and Analysis laboratory. 


\section{Results and Discussion}

During powder metallurgical processing via high-energy ball milling and FAST consolidation, we were concerned with two microstructural evolution processes. The first involves simultaneous mechanical mixing, grain size refinement, and particle size refinement during the high-energy ball milling process. The microstructures achieved in the powders will then evolve during sintering, which potentially involves thermal coarsening, precipitation of one or more second phases, and texturing. Here, we first map out microstructural transitions during the milling process with a focus on phase, grain size, and texture evolution as a function of milling time. Thermal stability of the achieved nanostructures is then assessed through isothermal heat treatments targeting temperatures below and above the typical recrystallization temperature for pure W. Finally, the effect of sintering on the nanostructures achieved during milling is mapped at the same temperatures employed for annealing of the ternary alloy powders and benchmarked against pure coarse-grained $W$ sintered under identical conditions.

\subsection{Mechanical Alloying and Grain Size Refinement during High-Energy Ball Milling}

A powder blend of nominal chemistry W-10Ti-20Cr was high-energy ball-milled using the parameters summarized in the methods section with milling time explored as the primary processing variable. The bench-top XRD patterns for each time series milling run are shown in Figure 1 relative to a blended powder sample prior to milling. Peaks from elemental $\mathrm{W}, \mathrm{Cr}$, and Ti can be seen in the pattern for the blended powder sample, and only those peaks remaining as milling time was increased are shown for identification on the other patterns. After $6 \mathrm{~h}$ of milling, distinct reflections from the hexagonal close packed (HCP) Ti phase almost completely disappeared, leaving only a subtle shoulder on the primary (110) BCC W reflection deriving from the convolution of the two lowest angle HCP Ti peaks. This shoulder was completely eliminated after milling for $12 \mathrm{~h}$ and was indicative of complete dissolution of HCP Ti into the BCC W solid solution. While the peaks for the BCC Cr phase also decreased considerably in intensity with increasing milling time, indicating $\mathrm{Cr}$ was also dissolved into the BCC W solid solution, the (110) and (211) reflections remained after $12 \mathrm{~h}$ of milling. The presence of these minor BCC $\mathrm{Cr}$ peaks demonstrate that a small fraction of this phase remained in the powders under all milling conditions, which from the perspective of consolidation into bulk alloys, is desirable for promoting phase-accelerated sintering $[53,54]$.

Beyond the dissolution of alloying elements into the BCC W solid solution during milling, the primary $W$ peaks exhibited broadening with increasing milling time due to a reduction in the coherent scattering size, i.e., the grain size in these materials, and accompanied by an increase in the non-uniform microstrain resulting from the formation of a wide range of microstructural defects [59]. To quantify the size component from the degree of peak broadening, benchtop XRD patterns were acquired with grain size determined via the Rietveld method [60]. The shape of the W diffraction peaks, specifically their larger breadth at the base of the peaks and sharp convergence near the maximum intensities, necessitated the use of a dual grain size population in the refinements since a single population did not capture both features (evident in Figure 2a). By refining a dual grain size population with a defined average grain size, $d_{a v}$, that combines fine and coarse average size populations (i.e., $d_{a v}^{f}=11 \mathrm{~nm}$ and $d_{a v}^{c}=76 \mathrm{~nm}$, respectively) into the Rietveld parameters optimized for each dataset, we vastly improved the accuracy of the fit to the experimental diffraction patterns in Figure 2a. This fitting method was employed to determine the average and individual population grain sizes for each sample from the $\mathrm{XRD}$ data, and results are plotted as a function of milling time in Figure $2 \mathrm{~b}$.

For milling times up to $4 \mathrm{~h}, d_{a v}$ and $d_{a v}^{c}$ were comparable as the sharper diffraction peaks were dominated by the latter. At $6 \mathrm{~h}, d_{a v}$ markedly decreased to $\sim 55 \mathrm{~nm}$ and further converged toward $d_{a v}^{f}$ of $\sim 17 \mathrm{~nm}$ with increased milling time. This shift to the smaller population denotes refinement of the microstructure well into the nanocrystalline regime with the transition occurring between 4 and $6 \mathrm{~h}$ of milling. Similar grain sizes as well as 
bimodal grain size distributions have been reported in the milling of $W[25,36]$ and other BCC metals such as Fe [61]. The Rietveld refinements also provided a quantitative phase analysis given that distinct reflections could be indexed for each constituent, assuming the balance to be BCC W. As shown in Figure $2 b$, the phase fraction, $f$, of both minor solute phases, denoted $f_{T i}$ and $f_{C r}$ and for HCP Ti and BCC Cr, respectively, decreased up to $6 \mathrm{~h}$, at which point $f_{C r}$ plateaued to $\sim 5 \mathrm{wt} . \%$ while the HCP Ti component was eliminated. We note that our analysis accounted for the minor contributions from the subtle low-angle $\mathrm{HCP}$ Ti reflections remaining at 6 and $8 \mathrm{~h}$, and the absence of this shoulder at $12 \mathrm{~h}$ confirms Ti dissolved into the BCC W solid solution.

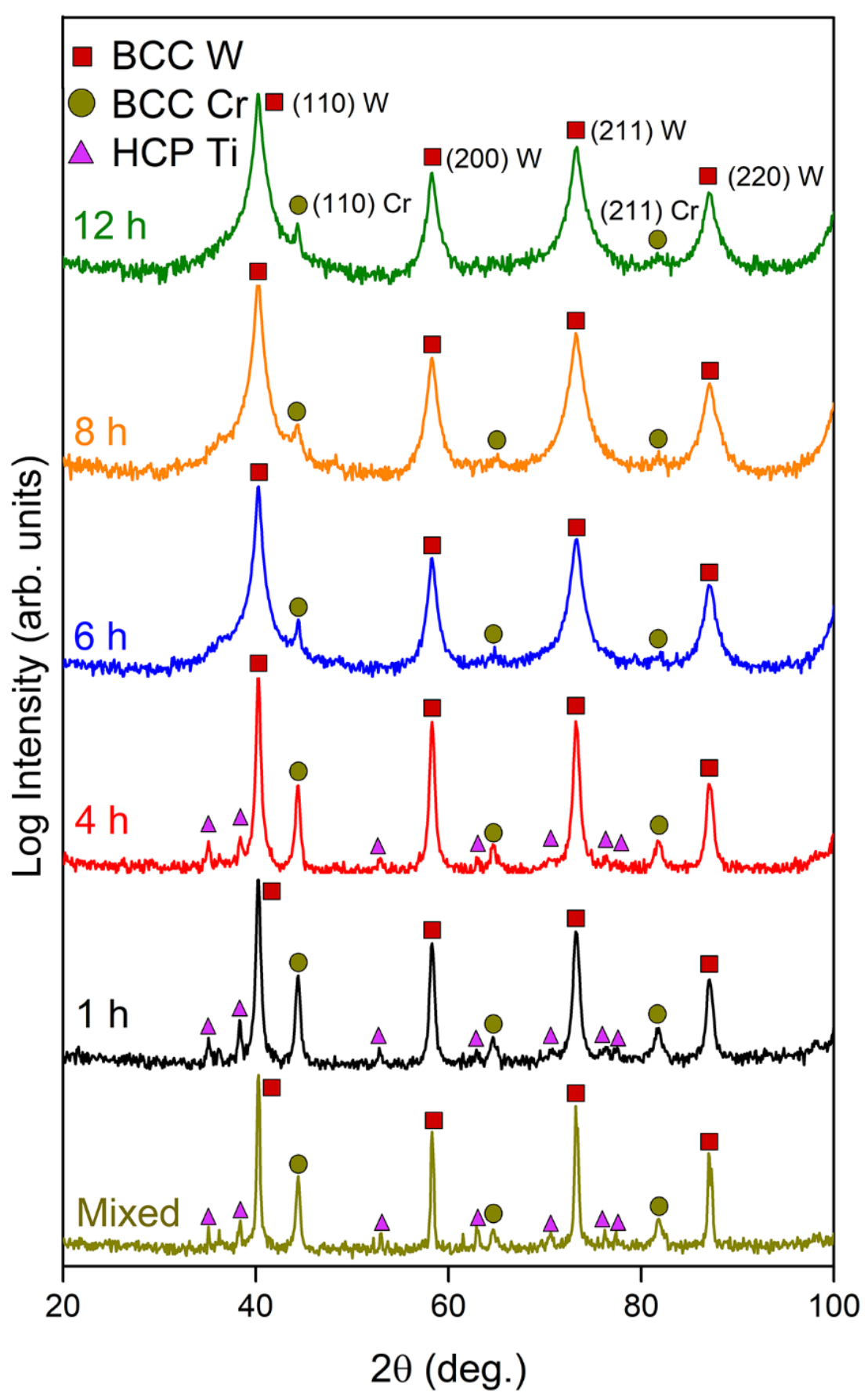

Figure 1. Synchrotron XRD patterns for the W-10Ti-20Cr powders milled to different times from 1-12 $\mathrm{h}$ relative to the mixed and unmilled elemental powders. Peaks corresponding to BCC W, BCC $\mathrm{Cr}$, and HCP Ti are indexed on each of the patterns. 

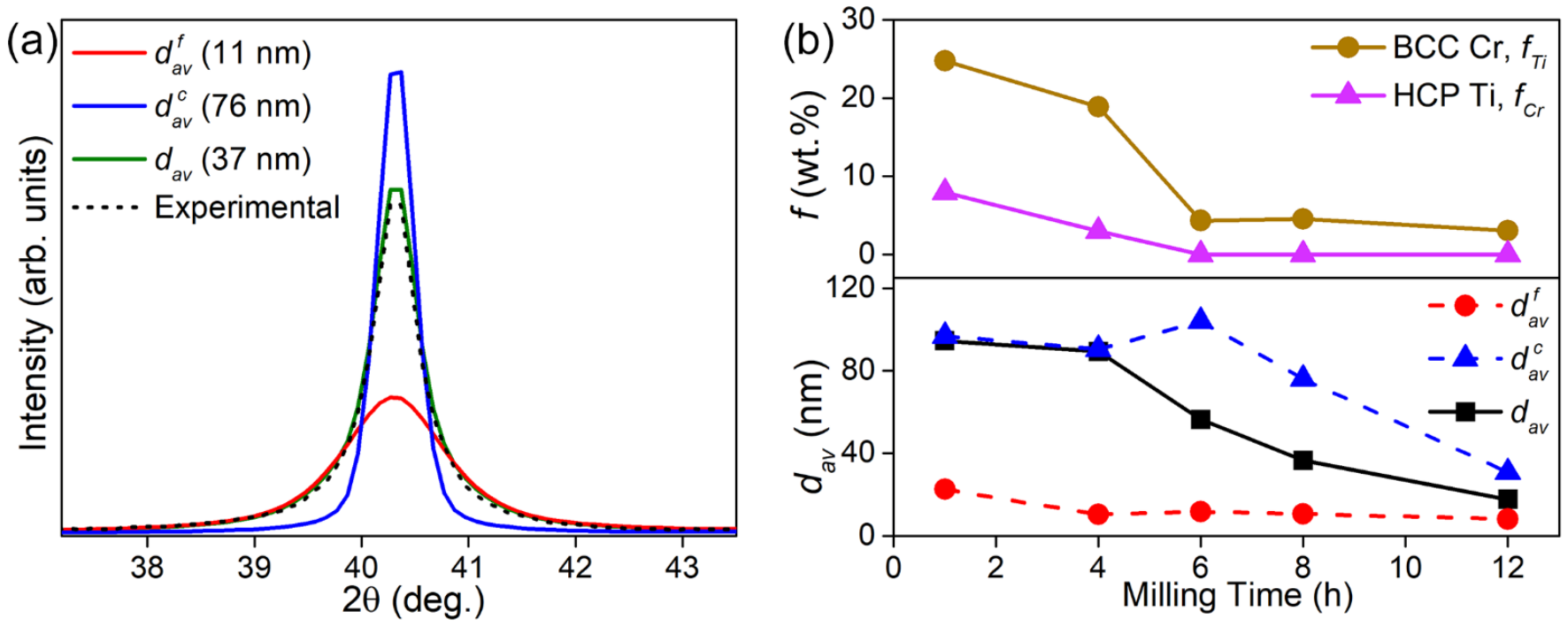

Figure 2. (a) Representative result from a Rietveld refinement for the (110) BCC W peak employing a dual grain size population with a fine and coarse mean grain size of $d_{a v}^{f}=11 \mathrm{~nm}$ and $d_{a v}^{c}=76 \mathrm{~nm}$, respectively. (b) Fraction of the BCC Cr and HCP Ti phases and average grain size as a function of milling time with the latter including the mean sizes for the two grain size populations used in the Rietveld refinements.

The dual grain size population was further investigated through STEM imaging of the milled powders prepared via FIB milling since initial attempts at finding electrontransparent regions in crushed powders proved unsuccessful. The low magnification STEM dark-field micrograph in Figure 3a reveals a heterogeneous microstructure with two distinguishable regions observed. Certain regions of the powder particles appeared to contain regularly shaped nanocrystalline grains, which was confirmed by the selected area electron diffraction (SAED) pattern shown in Figure $3 \mathrm{~b}$ acquired from within the region denoted location $i$. A large number of distinct spots derive from the many small grains simultaneously exhibiting the same crystallographic orientations for each of the respective diffraction rings for BCC W and consistent with a characteristic SAED ring pattern for the nanocrystalline state. A second region of the microstructure is apparent where the grain structure appears deformed, presumably due to plastic flow during the high-energy impact of the media during milling. A SAED pattern acquired on the region denoted location $i i$ is shown in Figure 3c. In contrast to the SAED pattern from location $i$, fewer spots are present on each diffraction ring, indicative of larger grains, and the intensity distributions suggestive of subtle texturing in this region of the sample [62].

The SAED patterns demonstrate two coexisting microstructures in the milled powders, one containing a fine nanocrystalline grain size and a second with coarser grains and a subtle degree of texturing. Higher magnification imaging of region $i$ shown in Figure 4a confirms the presence of fine equiaxed nanocrystalline grains with sizes in the range of 10-20 nm and consistent with the mean grain size reported from XRD analysis on the $12 \mathrm{~h}$ milled powders. The STEM dark-field image in Figure $4 \mathrm{~b}$ depicts region $i i$ where the grains are elongated and exhibit a wider range of sizes, suggesting this region of the microstructure was still undergoing deformation and grain size refinement later into the milling process. Such microstructures have been observed in milled W powders [63-66] and, given its transient nature relative to the equiaxed region, will be referred to as the transitional region. The presence of larger elongated grains in the transitional region agreed with the mean sizes of larger grain size population used in producing the sharper peak in Figure $2 b$ for the final fitting function. Additionally, the mean size employed for the small grain size population shown in the same figure were generally consistent with the fine grain size in the equiaxed region. Subtle discrepancies at longer milling times were 
attributed to the accuracy of convoluting two grain size populations in the fit of a single diffraction peak. The distinct grain size distributions in the equiaxed and transitional regions thus substantiate the use of bimodal grain size distributions for fitting the XRD patterns in Figure 2a. Finally, we note that texturing, as suggested by the SAED patterns, appears to be present in the transitional microstructure but not in the equiaxed regions containing the extremely fine nanocrystalline grains. The evolution of this texture and its implications for grain refinement are explored in the next section.
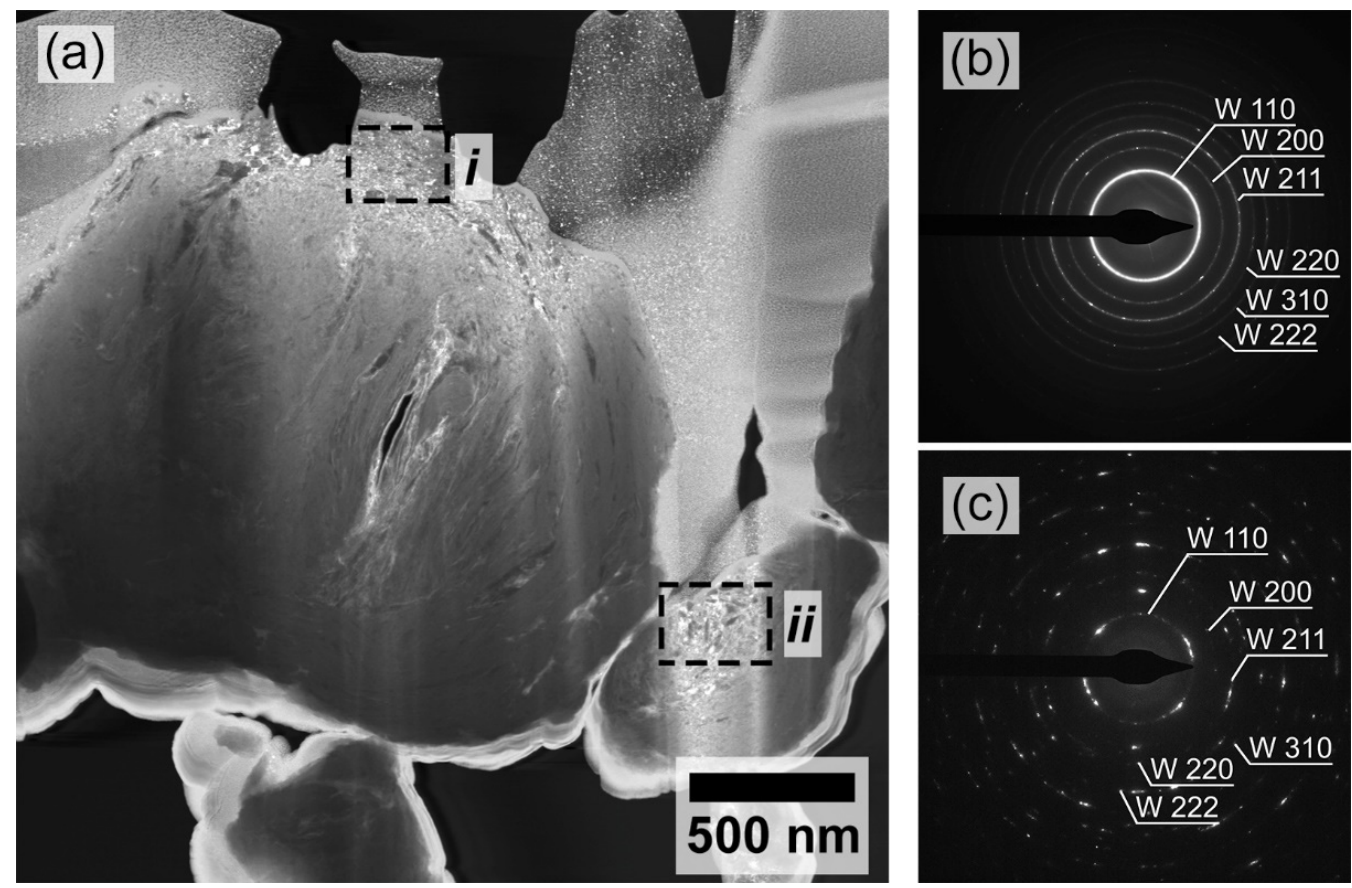

Figure 3. (a) STEM darkfield micrograph of two $\mathrm{W}-10 \mathrm{Ti}-10 \mathrm{Cr}$ particles milled for $12 \mathrm{~h}$ revealing regions of different grain sizes. SAED patterns acquired on $(\mathbf{b})$ the equiaxed microstructure in region $i$ and (c) the transitional microstructure in region $i i$ with diffraction rings indexed for BCC W.
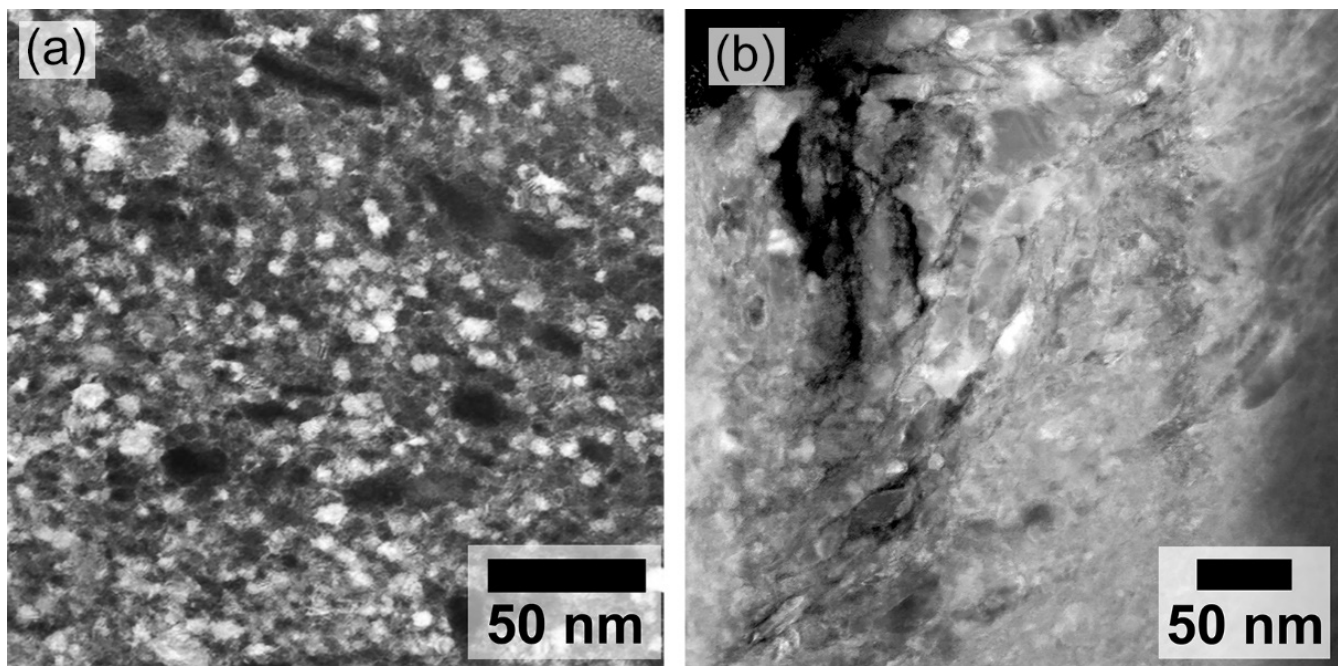

Figure 4. High magnification STEM darkfield images of the two regions outlined in Figure 3 on the $\mathrm{W}-10 \mathrm{Ti}-10 \mathrm{Cr}$ powders milled for $12 \mathrm{~h}$. (a) Region $i$ revealing the equiaxed grain structure. (b) Region $i i$ revealing elongated grains in a flow pattern and referred to herein as the transitional grain structure. 


\subsection{Texture Evolution and Its Implications for Powder Morphologies}

As suggested by the multi-modal nature of the grain structure, the powder experienced transitions in its microstructure that derive from the high deformation energy promoting successive and repeated cold working, welding, and fracturing of the powder particles [40]. BCC metals exhibit preferred $\{110\}$ and $\{112\}$ slip [67-69], which, as demonstrated in forged powder metallurgy Ta, leads to preferred texture formation from feedstock material with random initial crystallographic orientations [70]. Transient texturing can thus be expected to result from a high-energy deformation process such as ball milling, which will ultimately impact the powder particle morphology and size distribution. The latter is generally determined by the rate of cold welding and subsequent fracture, and both occur simultaneously during ball milling. Initially, cold welding dominates, often leading to coarsening of the powder particles. This process eventually transitions to fracture as the grain size is refined with a concomitant decrease in the particle size [13]. Particle size distributions for the $\mathrm{W}$ alloy are shown in Figure 5a with increasing milling time from bottom to top relative to the starting distribution for the feedstock $\mathrm{W}$ powder.

Initially, the milled powders coarsened for times of up to $4 \mathrm{~h}$ and accompanied by a transition in the particle morphologies from spherical for the $\mathrm{W}$ feedstock powder, as shown in the scanning electron micrograph in Figure 5b, to platelet-like geometries in Figure 5c. This morphological transition is consistent with the study by Wu et al. [16] on the effect of media-to-powder ratio and indicative of a high rate of cold welding [17] combined with deformation along preferred slip systems in the coarse grain $\mathrm{W}$ powders [18]. Milling for additional time produced a rapid reduction in the particle size between 4 and $6 \mathrm{~h}$, which we attributed to the dominant mechanism shifting toward fracture due to refinement of the grain size during this period, as shown in Figure $2 b$. Subsequent broadening of the particle size distribution, and a transition back to spherical morphologies as shown in Figure $5 \mathrm{~d}$ after a milling time of $12 \mathrm{~h}$, occurred from 6 to $12 \mathrm{~h}$. During this period, the rate of grain size reduction was markedly less than the initial transition period between 4 and $6 \mathrm{~h}$, eventually plateauing to a steady-state value of approximately $10 \mathrm{~nm}$. With grain size refinement contributing less to kinetic energy dissipation, the observations of particle coarsening, and emergence of a bimodal size distribution suggest cold welding and fracture governs additional evolution of the powders at longer milling times. However, due to the fine nanocrystalline grain sizes, deformation no longer transpires along favorable slip systems and is instead accommodated by grain boundary mediated mechanisms [71], thus providing an explanation for the emergence of spherical powder morphologies rather than the formation of platelets.

Thus far, our discussion of texturing and its implications for the deformation process during milling has relied on established knowledge of the slip process in BCC metals and morphological evolution of the powders as a function of milling time. However, the emergence of the platelet-like particle morphologies provides an opportunity to probe this connection through XRD measurements on deliberately aligned powders for sampling the underlying crystallographic texture. Compared with a random powder arrangementdenoted "random packing" - in a traditional side-loaded XRD sample holder, as illustrated in Figure 6a, and shown for an actual powder sample, a top-loaded sample holder was employed, allowing for the powders to be introduced under an applied force. The plateletlike geometries align under this force such that the faces of larger surface area powder particles become oriented with the incident $X$-ray beam, as illustrated in Figure 6b. Denoted "oriented packing" and demonstrated for an actual powder sample in the SEM micrograph, this diffraction orientation will allow for probing of potential crystallographic texture associated with the flattening of the powder particles and in turn, platelet formation during milling. 


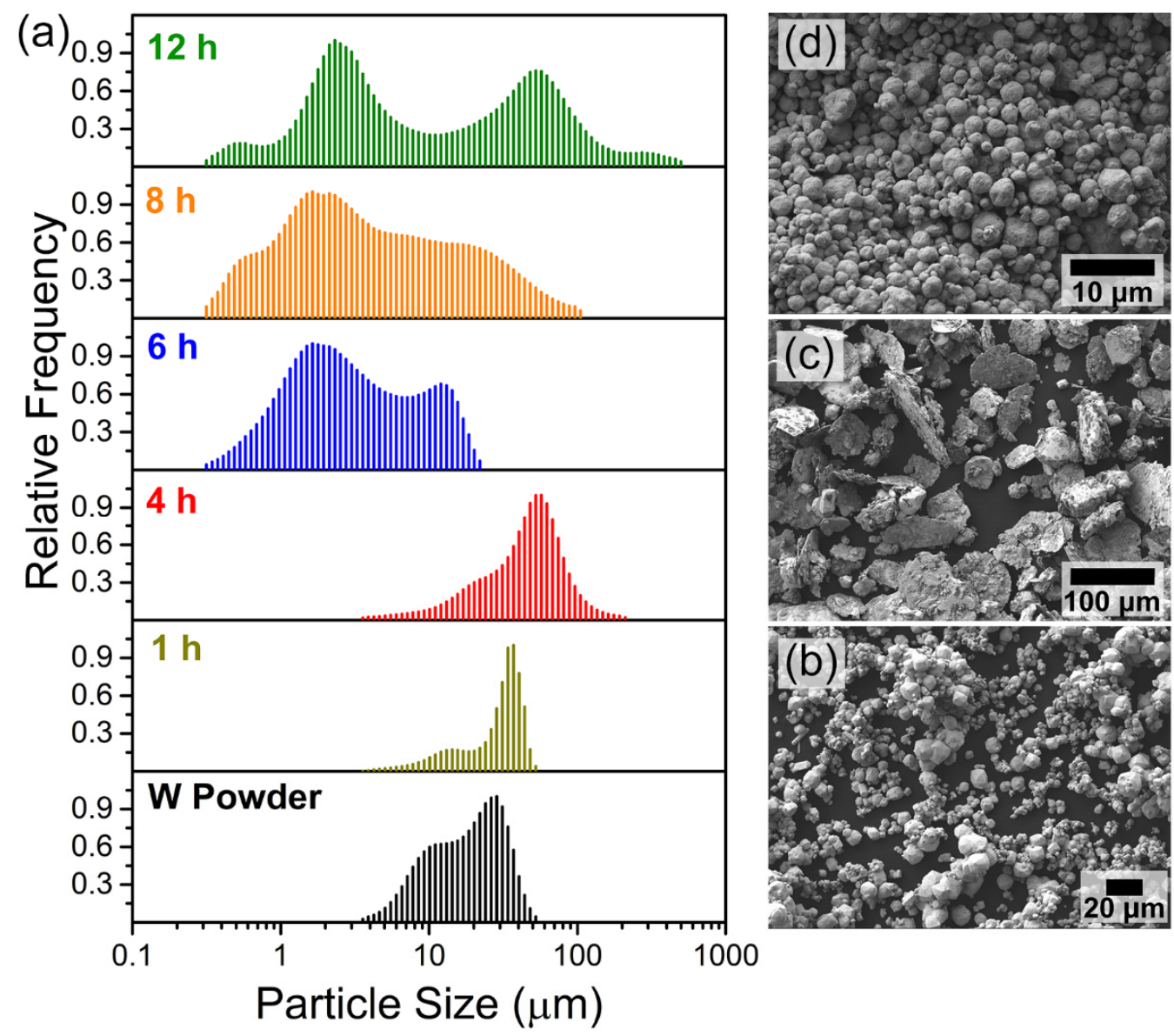

Figure 5. (a) Particle size distributions for the W-10Ti-20Cr powders milled to different times with the size distribution of the starting $\mathrm{W}$ powder feedstock shown for reference. Backscatter SEM micrographs of powders (b) mixed and blended prior to milling, then following milling for (c) $4 \mathrm{~h}$, and (d) $12 \mathrm{~h}$. The transitions from faceted to platelet particle morphologies and subsequently from platelet to spherical are evident from $(\mathbf{b}-\mathbf{d})$.

The orientation dependence for the different packing configurations is revealed in the bench-top XRD patterns in Figure 7a for the W-10Ti-20Cr powders milled for $4 \mathrm{~h}$, shown previously to exhibit sharp platelet powder morphologies (cf. Figure $5 \mathrm{c}$ ). While the $\{110\}$ family of BCC W peaks, and to a lesser extent, the (211) peak, exhibited comparable intensities, the intensity of the (200) peak acquired on the oriented packing sample was considerably larger than the same peak intensity from the randomly packed sample. This effect is mapped for all powder samples as a function of milling time using the intensity of the (200) peak normalized to the primary (110) peak in Figure $7 \mathrm{~b}$ to account for extrinsic intensity differences between the different samples. For the un-milled $W$ powder, the ratio of the (200) to (110) peak intensities is consistent with the value reported for $W$ with a random polycrystalline texture [72]. Conversely, the milled powders in both packing configurations exhibited an increase in the magnitude of the (200)/(110) peak ratio at intermediate milling times, which was markedly accentuated in the samples with oriented packing and indicative of (200) texturing in this diffraction orientation. Milling times of $\geq 8 \mathrm{~h}$ produced a decrease in the $(200) /(110)$ peak ratio with eventual convergence to the random polycrystalline $\mathrm{W}$ texture, thus confirming elimination of crystallographic texture as suggested by the morphological evolution of the powders. 
(a)
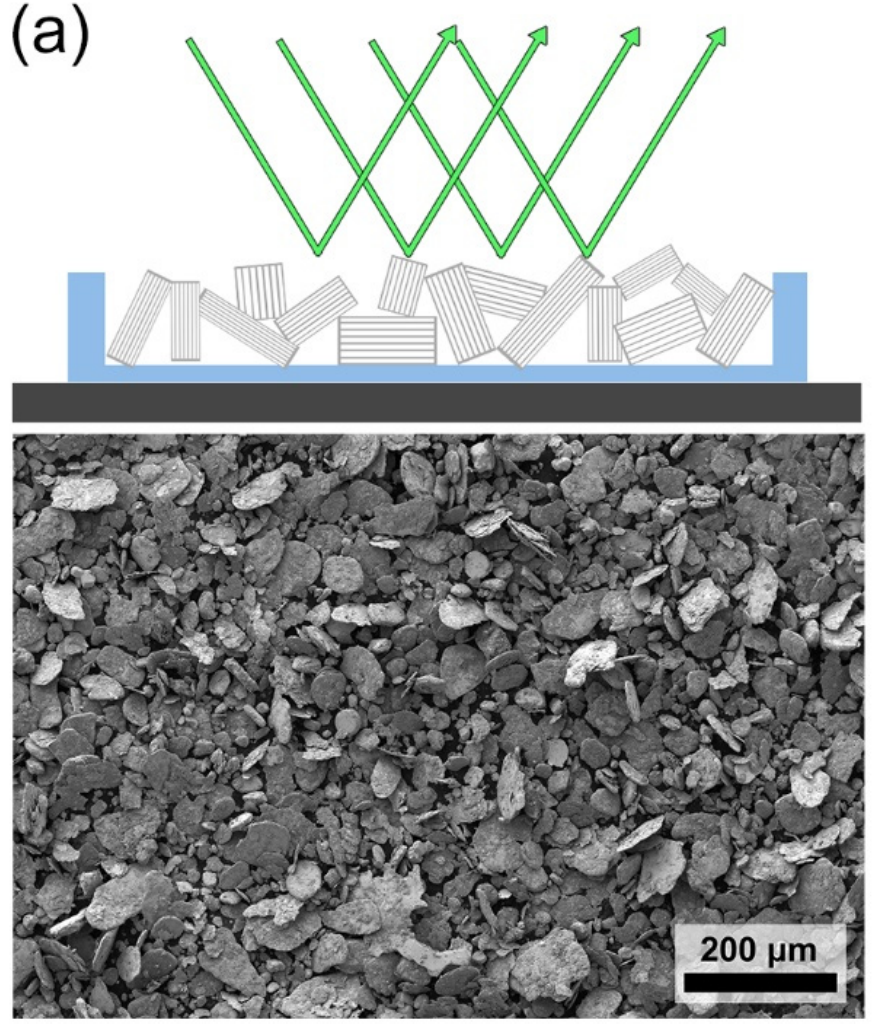

(b)
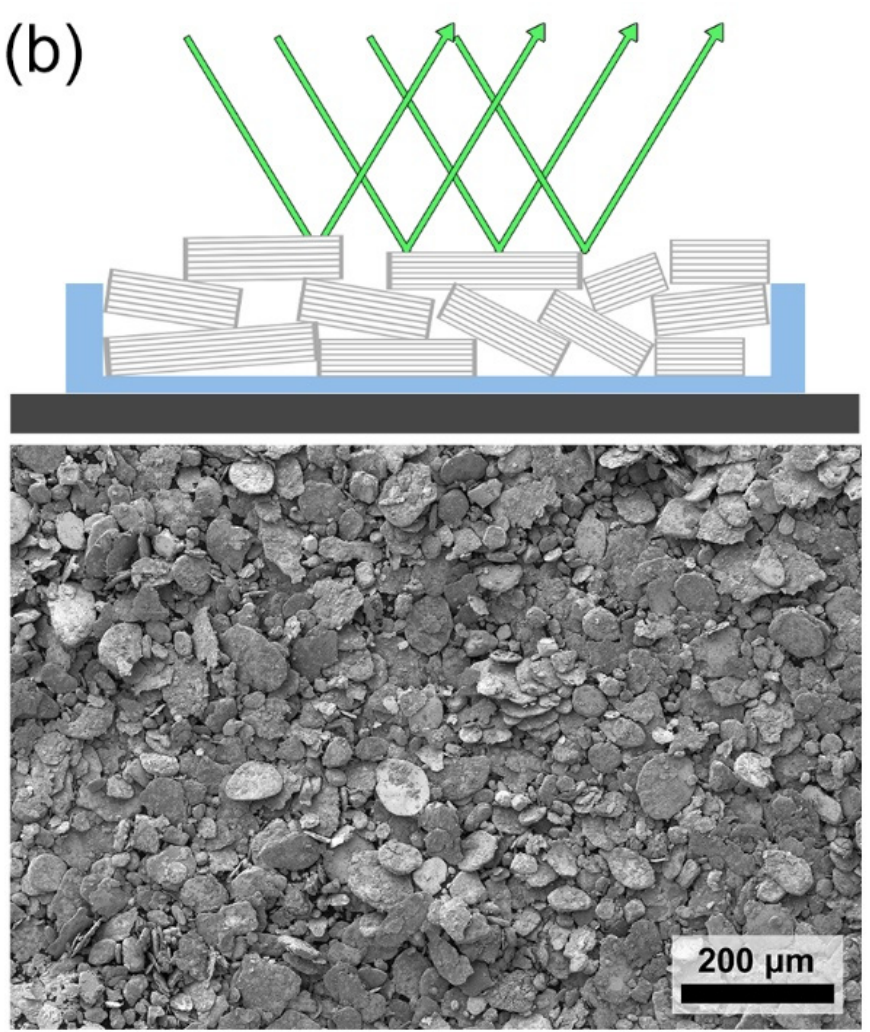

Figure 6. Schematic illustrations and SEM micrographs of the W-10Ti-20Cr powders milled for $4 \mathrm{~h}$ and loaded into the XRD sample holder in (a) random and (b) oriented packing configurations. The latter generally aligned the flat particle faces with the incident $\mathrm{X}$-ray beam.
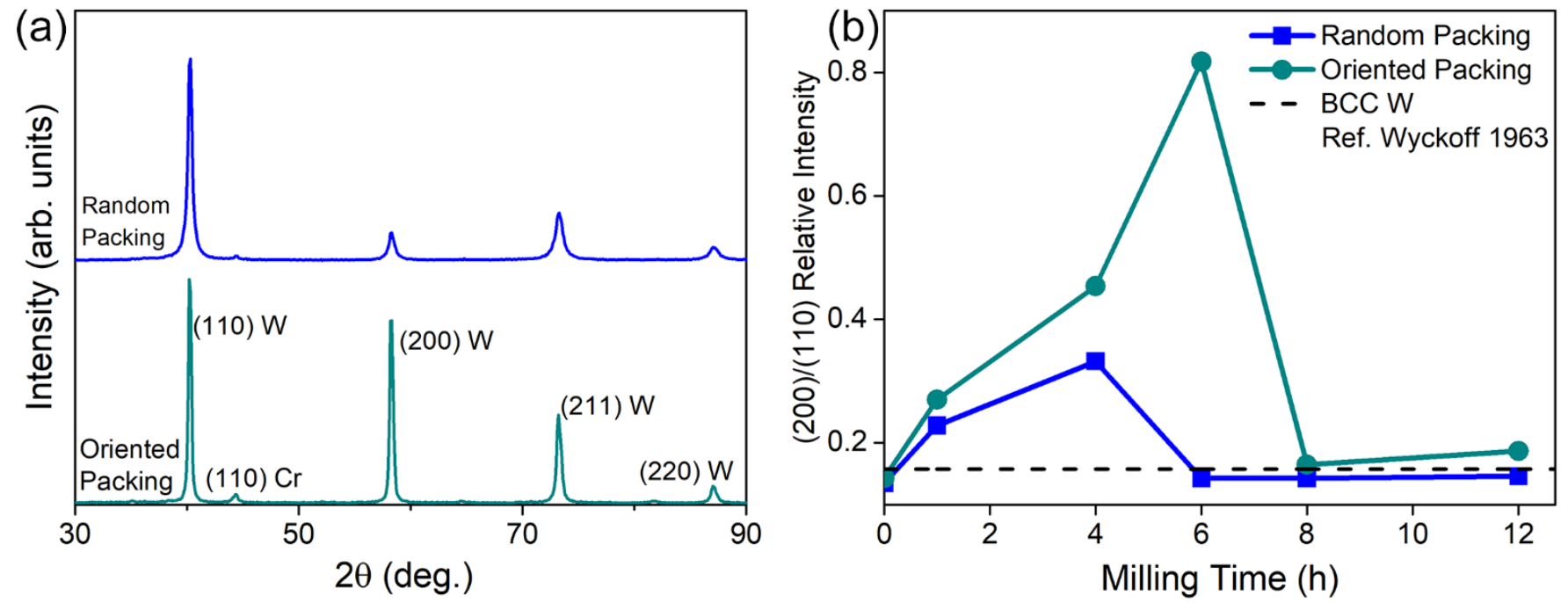

Figure 7. (a) Bench-top XRD patterns for W-10Ti-20Cr powder samples loaded in random and oriented packing configurations. (b) Relative intensity of the (200) peak to the primary (110) peak as a function of milling time for random and oriented packing powder configurations. The dashed line represents the value reported for $\mathrm{W}$ with a random polycrystalline texture from Reference [72].

Texture evolution during the deformation processing of BCC metals involves the formation of three primary fiber textures: (i) $\alpha$-fiber containing $<110>$ parallel to the rolling direction with $\{001\}<110>,\{112\}<110>$, and $\{111\}<110>$ orientations, (ii) $\gamma$-fiber containing $<111>$ parallel to the normal direction with $\{111\}<110>$ and $\{111\}<112>$ orientations, and 
(iii) $\theta$-fiber containing $<001>$ parallel to the to the normal direction with $\{001\}<110>$ and $\{001\}<100>$ orientations [73]. Simulations employing a Taylor-type grain interaction model have shown that $\alpha$ - and $\gamma$-fiber textures emerge when slip is constrained to the $\{110\},\{112\}$, and $\{123\}$ planes all along the $<111>$ direction [74] and is consistent with experimentally determined fiber textures in BCC transition metals [75-77]. However, a recent study on unidirectionally cold-rolled $W$ indicated that the $\gamma$-fiber was accompanied by both a Goss texture with $(011)<110>$ orientation and $\theta$-fiber with $\{001\}<100>$ orientation, both of which peaked at $80 \%$ reduction prior to the $\gamma$-fiber becoming dominant at $90 \%$ [78]. Unidirectional rolling was also found to produce a strong $\{001\}<100>\theta$-fiber texture in Ta at intermediate strains, which like $\mathrm{W}$, transitioned to the $\gamma$-fiber as deformation approached $90 \%$ reduction [79].

During the milling of our $\mathrm{W}-10 \mathrm{Ti}-20 \mathrm{Cr}$ powders, we reported a significant increase in the (200) peak intensity at intermediate milling times with the powders in the oriented packing configuration. While the stress state during particle deformation in ball milling is difficult to predict and decidedly different than uniaxial rolling, it will involve both compression and shear stress components. In the $\theta$-fiber texture developed during rolling, the $<001>$ is orthogonal to the rolling direction and parallel to the normal direction with orientation $\{001\}<100>$. The observed (200) texture at intermediate milling times is thus consistent with the formation of a $\theta$-fiber texture, which is preferred at intermediate strains in $\mathrm{W}$ [78]. Referring to the grain size trend in Figure $2 \mathrm{~b}$ and specifically the sharp decline between 4 and $6 \mathrm{~h}$, it is now apparent that this texturing process facilitates grain size refinement during high-energy ball milling of $\mathrm{W}$ and aligns with observations of coupled grain size reduction and texture evolution during rolling [80]. Non-uniform texturing effects, as described in Lied et al. [75], will also promote coexisting equiaxed and transitional microstructures since strain accommodation depends on the specific crystallographic texture and thus will influence the rate of grain size refinement in different regions of the microstructure.

\subsection{Thermal Stability of Ternary Nanostructured W Alloy Powders}

With an understanding of the powder's microstructure and morphology in the asmilled condition, analyzing the effects of annealing draws a connection between the asmilled powder characteristics and how they impact the thermal stability of the material. It is well established that nanocrystalline materials with an increased volume fraction of grain boundaries experience thermal instabilities, which can be combated by targeted doping as shown previously in $W[2,36,54]$. Of particular interest here is thermal stability in our ternary alloy system where both alloying elements- $\mathrm{Ti}$ and $\mathrm{Cr}$-have an affinity for grain boundary segregation with the potential to augment stability relative to the binary systems previously studied. Annealing experiments were thus performed on W-10Ti-10Cr powders milled for $12 \mathrm{~h}$ at temperatures up to $130{ }^{\circ} \mathrm{C}\left(0.38 \mathrm{~T}_{\mathrm{m}}\right)$, which is above the typical recrystallization temperature of unalloyed $W$ [45-48]. The reduction in the $\mathrm{Cr}$ content to 10 at.\% was to minimize retained BCC Cr in the as-milled powder, which should instead be precipitated during high temperature processing to facilitate effective sintering at reduced temperatures [53].

The XRD patterns for the $\mathrm{W}$-10Ti-10Cr powders annealed at $1000{ }^{\circ} \mathrm{C}, 1150{ }^{\circ} \mathrm{C}$ and $1300{ }^{\circ} \mathrm{C}$ are shown in Figure 8 relative to a pattern for the as-milled powder. The degree of peak broadening was comparable to the pattern for the as-milled W-10Ti-20Cr powder milled for the same time ( $12 \mathrm{~h})$ shown in Figure 1, indicating that the minimum achievable grain size was not impacted by the reduction in the $\mathrm{Cr}$ concentration. Conversely, the reduced intensity of the (110) BCC Cr peak indicates a smaller fraction of Cr was retained in the as-milled powder and consistent with the reduction in the $\mathrm{Cr}$ concentration from 20 to 10 at.\%. Broad peaks and the small fraction of BCC Cr were maintained through annealing at $1000{ }^{\circ} \mathrm{C}$, demonstrating stability of the as-milled nanostructure up to this temperature. A further increase in the annealing temperature to $1150{ }^{\circ} \mathrm{C}$ was accompanied by subtle sharpening of the primary BCC W peaks, which signals the grain structure coarsened at this temperature. As evidenced by the disappearance of the (110) BCC Cr peak, the Cr-rich phase 
dissolved, and was consistent with the bulk phase diagram, since $1150{ }^{\circ} \mathrm{C}$ lies convincingly outside the miscibility gap for a W-10 at.\% Cr alloy [81]. However, the degradation of WC media during high-energy ball milling introduced $\mathrm{C}$ impurities into the milled powders with a non-negligible concentration of $0.47 \mathrm{wt} . \%$, which resulted in a small fraction of face-centered cubic (FCC) TiC precipitated at this temperature. Carbide formation was exacerbated at $1300{ }^{\circ} \mathrm{C}$ with the TiC phase accompanied by $\mathrm{M}_{23} \mathrm{C}_{6}$ precipitating in the $\mathrm{W}$ solid solution. The metal sublattice of this carbide (denoted $\mathrm{M}$ in the chemical formula) is predominantly $\mathrm{Cr}$, but subtle lattice parameter shifts indicated atomic substitution of $\mathrm{Ti}$ and $\mathrm{W}$ on this sublattice. The formation of both carbides thus acts to deplete both $\mathrm{Ti}$ and $\mathrm{Cr}$ from the $\mathrm{W}$ solid solution, which effectively reduces grain boundary solute enrichment and, in turn, promotes coarsening at elevated temperatures. This manifested as a sharpening of the primary BCC W diffraction peaks in Figure 8, though we note peak broadening was still evident at $1300{ }^{\circ} \mathrm{C}$ and indicative of a fine-grained microstructure despite carbide-induced instabilities.

The average grain size of the powders along with the mean size of the two populations employed in fitting the synchrotron XRD patterns are shown in Figure 9a as a function of annealing temperature relative to the as-milled powder. Tracking of the grain size populations used in fitting the diffraction peaks indicated that, up to $1000{ }^{\circ} \mathrm{C}$, coarsening was primarily concentrated with the coarse grain size captured by the $d_{a v}^{c}$ trend and consistent with sharpening of the diffraction peaks limited primarily to their centers while broadening was still evident around the bases. From the texture analysis, these regions of the microstructure were still experiencing grain size refinement and mechanical alloying. Consequently, this transient region of the microstructure will contain grain boundaries lean in solute, which, based on the description of a thermodynamically preferred alloy configuration (e.g., by the regular nanocrystalline solution model [33,35]), would represent an unstable part of the microstructure. The grain size of the equiaxed nanocrystalline region of the microstructure retained the as-milled grain size of $\sim 10 \mathrm{~nm}$, which is substantiated in the high magnification STEM darkfield image of the equiaxed nanocrystalline grain structure in Figure $9 \mathrm{~b}$. Conversely, at $1150{ }^{\circ} \mathrm{C}$ and $1300{ }^{\circ} \mathrm{C}$, grain growth transpired in both the coarse and fine grain size populations, effectively producing an overall increase in the average grain size as captured in the $d_{a v}$ trend and a result of the carbide induced instability mechanism described above. Nevertheless, the ternary nanocrystalline W-10Ti-10Cr alloy was stable up to $1000{ }^{\circ} \mathrm{C}$ with an average grain size $\sim 25 \mathrm{~nm}$, while above the recrystallization temperature up to $1300{ }^{\circ} \mathrm{C}$, remained nanostructured albeit with distributed carbides and a larger average grain size.

\subsection{Nanostructure Evolution and Precipitation during Field Assisted Sintering}

Annealing of the milled powders revealed that while the $\mathrm{W}-10 \mathrm{Ti}-10 \mathrm{Cr}$ alloy remained nanocrystalline up to $1300{ }^{\circ} \mathrm{C}$, small fractions of carbides ( $<2 \mathrm{wt}$. \%) formed due to the $\mathrm{C}$ impurities introduced from the WC media during milling. The measured $\mathrm{C}$ concentration was 0.47 wt. $\%$, which translates to 5.84 at. $\%$. When compared with the measured Ti and $\mathrm{Cr}$ concentrations of 9.10 and 9.30, respectively, this amount of $C$ is non-negligible and demonstrates that high-energy ball milling with the selected media inevitably produced a quaternary alloy. Coarsening of the nanostructure above $1000^{\circ} \mathrm{C}$ is thus a consequence of these $C$ impurities driving carbide formation and the associated depletion of the stabilizing solute elements from the $\mathrm{W}$ solid solution. While there are other media choices, such as hardened steel, WC was deliberately selected to avoid the incorporation of metal impurity species. Future work will focus on alloy modifications and optimization of the milling process to minimize the amount of $C$ introduced during milling. Nonetheless, with the caveat that $C$ impurities are expected to produce carbides during sintering, we map the sintering behavior of the W-10Ti-10Cr alloy as a function of temperature given that the nanophase separation sintering mechanism suppressed the sintering temperature to $\sim 1000{ }^{\circ} \mathrm{C}$ in the binary nanostructured W-Cr system [53]. 


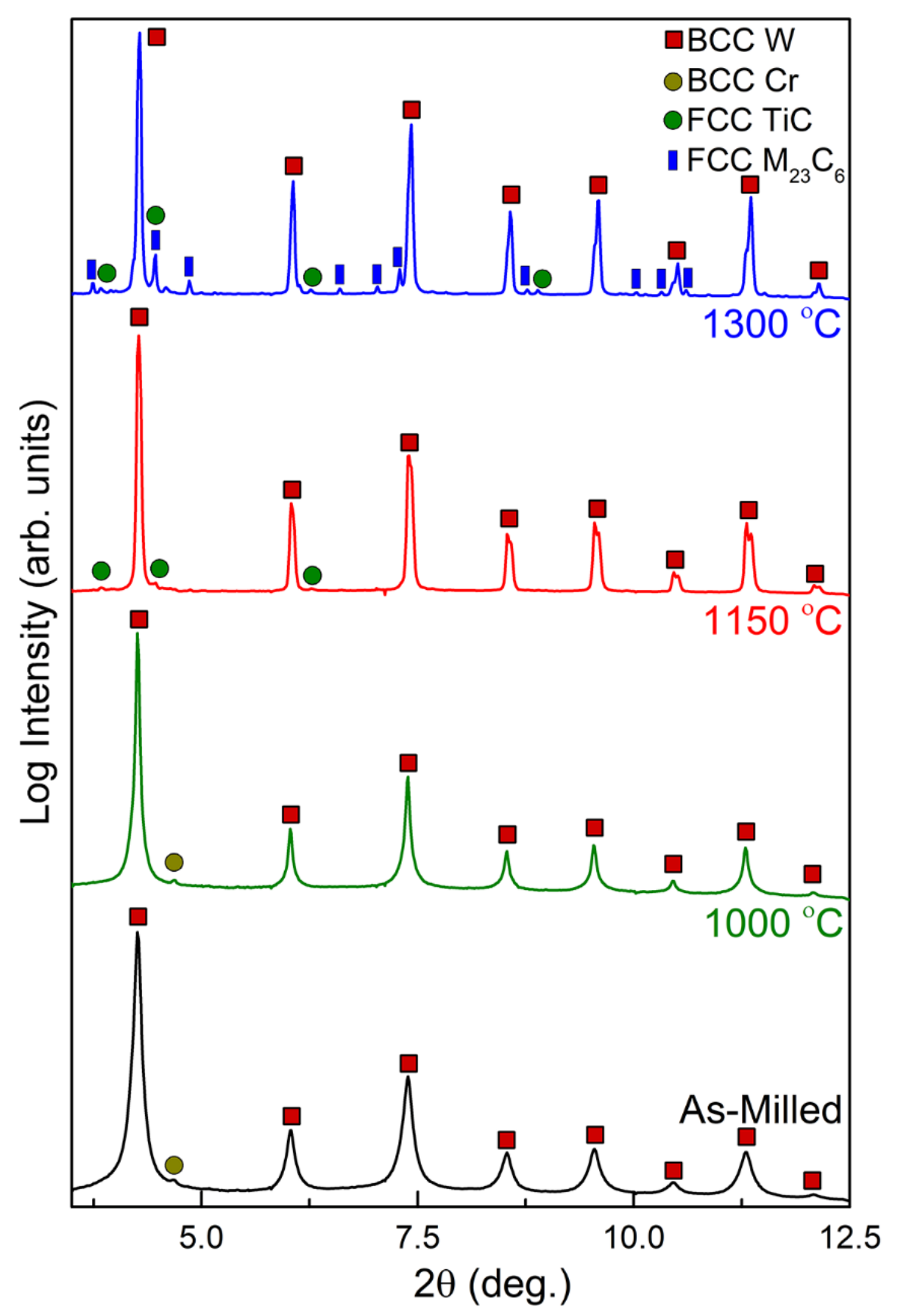

Figure 8. Synchrotron $\mathrm{XRD}$ patterns of the $\mathrm{W}-10 \mathrm{Ti}-10 \mathrm{Cr}$ powders milled for $12 \mathrm{~h}$ shown in the asmilled condition and following a 1-h heat treatment at $1000^{\circ} \mathrm{C}, 1150{ }^{\circ} \mathrm{C}$ and $1300{ }^{\circ} \mathrm{C}$. Indexed phases include $\mathrm{BCC}$ W, BCC Cr, FCC TiC, and $\mathrm{FCC} \mathrm{M}_{23} \mathrm{C}_{6}$; however, distinct crystallographic reflections are deliberately not included alongside each peak for clarity of presentation.

Sintering curves are depicted in Figure 10a for an as-milled W-10Ti-10Cr alloy powder and a coarse-grained unalloyed W (CG-W) powder where the 5 min hold at elevated temperature was conducted at $1200^{\circ} \mathrm{C}$. Data is displayed as an expansion corrected platen displacement, referred to as corrected displacement, that accounts for the thermal expansion of the graphite die and powder charge. Positive displacements coincided with the direction of the applied compressive force and was indicative of powder compaction within the graphite die. At temperatures below $\sim 400{ }^{\circ} \mathrm{C}$, the powder charge was initially densified through the elimination of free space within the powder charge under the combined application of the external compressive load and ramping up of the temperature. Further 
increases in temperature produced little change in the platen displacement up to the point where sintering initiated, which transpired at $1200{ }^{\circ} \mathrm{C}$ for the unalloyed $\mathrm{W}$ powder charge and thus coincided with the isothermal hold temperature employed in this experiment. Consequently, the densification of this sample was constrained to the isothermal hold period with limited platen displacement. Sintering the unalloyed powder at $1400{ }^{\circ} \mathrm{C}$ produced an identical curve, albeit with the consolidation period delayed to the higher isothermal hold temperature, further demonstrating that prolonged exposure at elevated temperature is required for the sintering of CG-W.
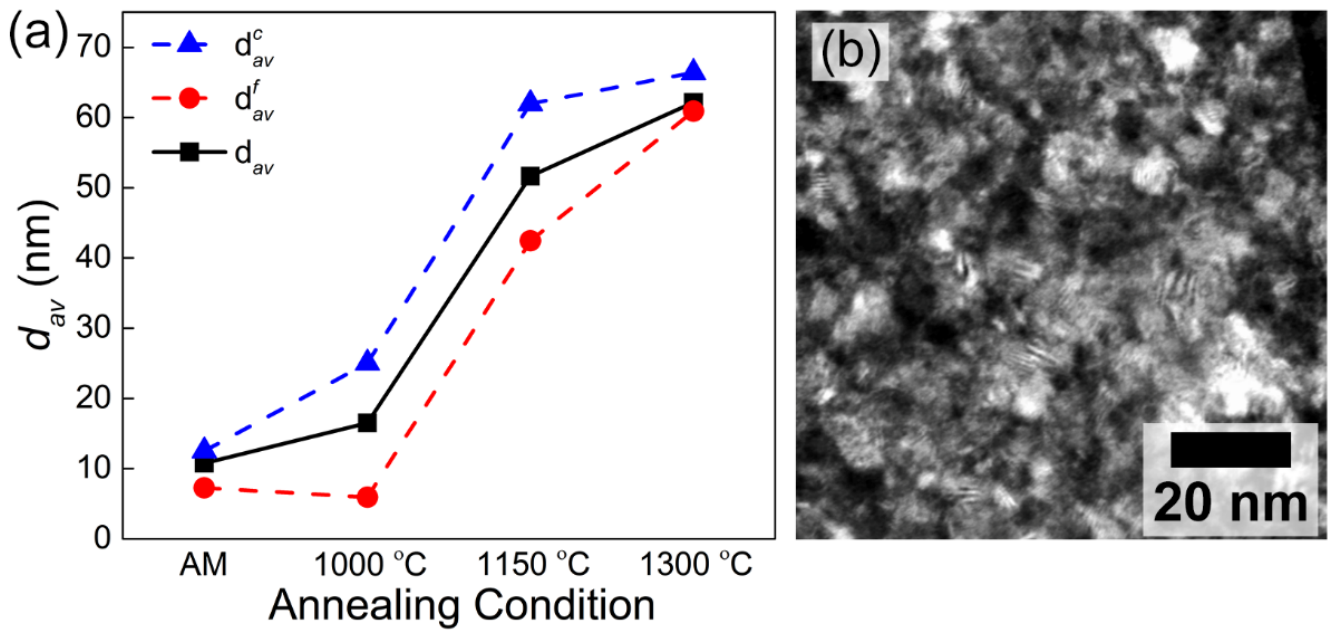

Figure 9. (a) Grain size as a function of temperature relative to the W-10Ti-10Cr powders milled for $12 \mathrm{~h}$. The two grain size populations denoted $d_{a v}^{f}$ and $d_{a v}^{c}$, used in the Rietveld refinements to determine the average grain size, $d_{a v}$, are included and revealed that the most significant increase in grain size transpired above $1000^{\circ} \mathrm{C}$. (b) High magnification STEM darkfield image taken from the fine nanocrystalline region of the equiaxed grain structure.
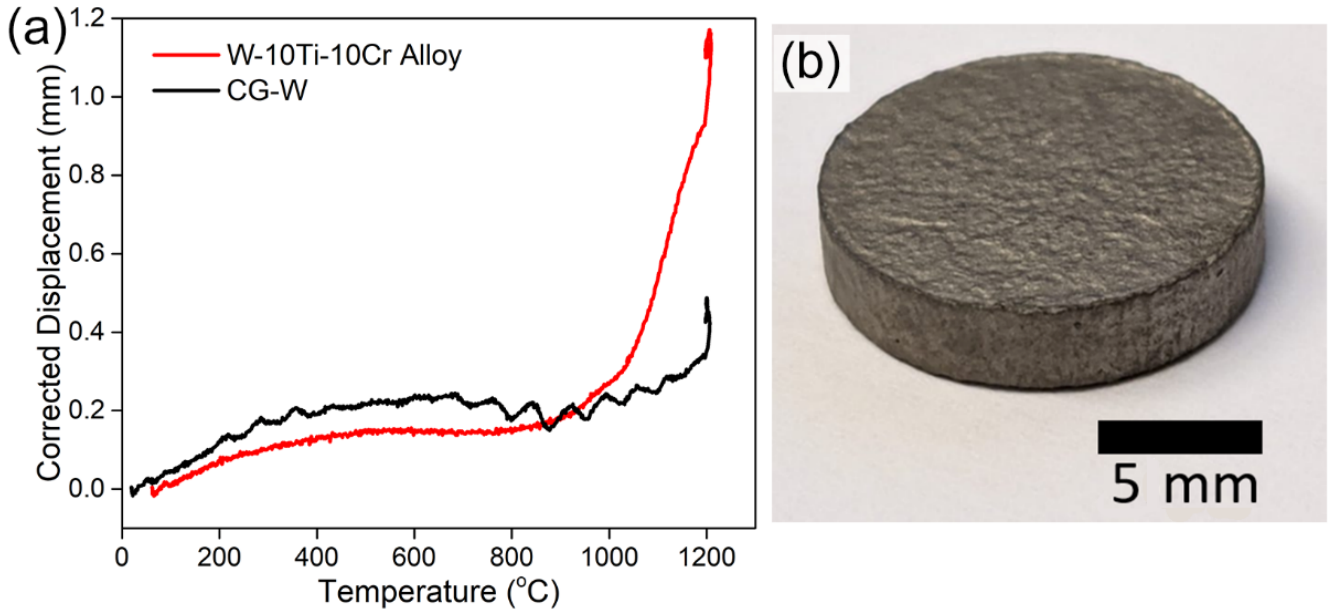

Figure 10. (a) Sintering curves for the nanocrystalline W-10Ti-10Cr powder and CG-W powder with displacement corrected for the thermal expansion of the die and powder charge. The onset of sintering in the nanocrystalline alloy was reduced to $\sim 1000{ }^{\circ} \mathrm{C}$ with a sintered bulk sample in (b).

The W-10Ti-10Cr alloy powder experienced densification at a markedly reduced temperature of $\sim 1000{ }^{\circ} \mathrm{C}$, well below the isothermal hold temperature of $1200{ }^{\circ} \mathrm{C}$, and with considerably enhanced platen displacement consistent with the binary nanocrystalline W-15 at.\% Cr alloy [53]. Consolidation instead with a maximum temperature and isothermal hold of $1400{ }^{\circ} \mathrm{C}$ produced identical sintering curves for the ternary alloy with platen 
displacement signaling the onset of sintering at $\sim 1000^{\circ} \mathrm{C}$, in agreement with a preliminary report of this behavior as summarized in a perspectives article on the future of multiscale modeling for fusion materials [82]. The excellent agreement between the sintering behavior of the previously studied binary system and the present W-10Ti-10Cr alloy demonstrates two important features of the ternary system. First, the presence of Ti does not inhibit the onset of consolidation through the reported nanophase separation sintering mechanism. This is particularly important since the addition of $\mathrm{Ti}$ is generally required to maintain the nanocrystalline state during high-temperature processing. Second, the reduction in the $\mathrm{Cr}$ concentration to 10 at.\% did not impact the degree of densification, which was significant relative to the bulk samples produced from the coarse-grained pure W powder. In Figure 11, the relative density of the bulk W-10Ti-Cr alloy was $~ 98 \%$ (accounting for the alloying additions) and independent of the maximum sintering temperature, further substantiating that sintering transpired well below the isothermal hold period. Conversely, the relative density for the unalloyed bulk W sample, denoted CG-W, was $<80 \%$ with the $1200{ }^{\circ} \mathrm{C}$ hold and increased to $\sim 92 \%$ at $1400{ }^{\circ} \mathrm{C}$. Not only does this confirm the temperature dependence of the sintering of unalloyed $\mathrm{W}$, but it also demonstrates the marked improvement in the sinter-ability of $\mathrm{W}$ enabled through the introduction of tailored compositional heterogeneities.

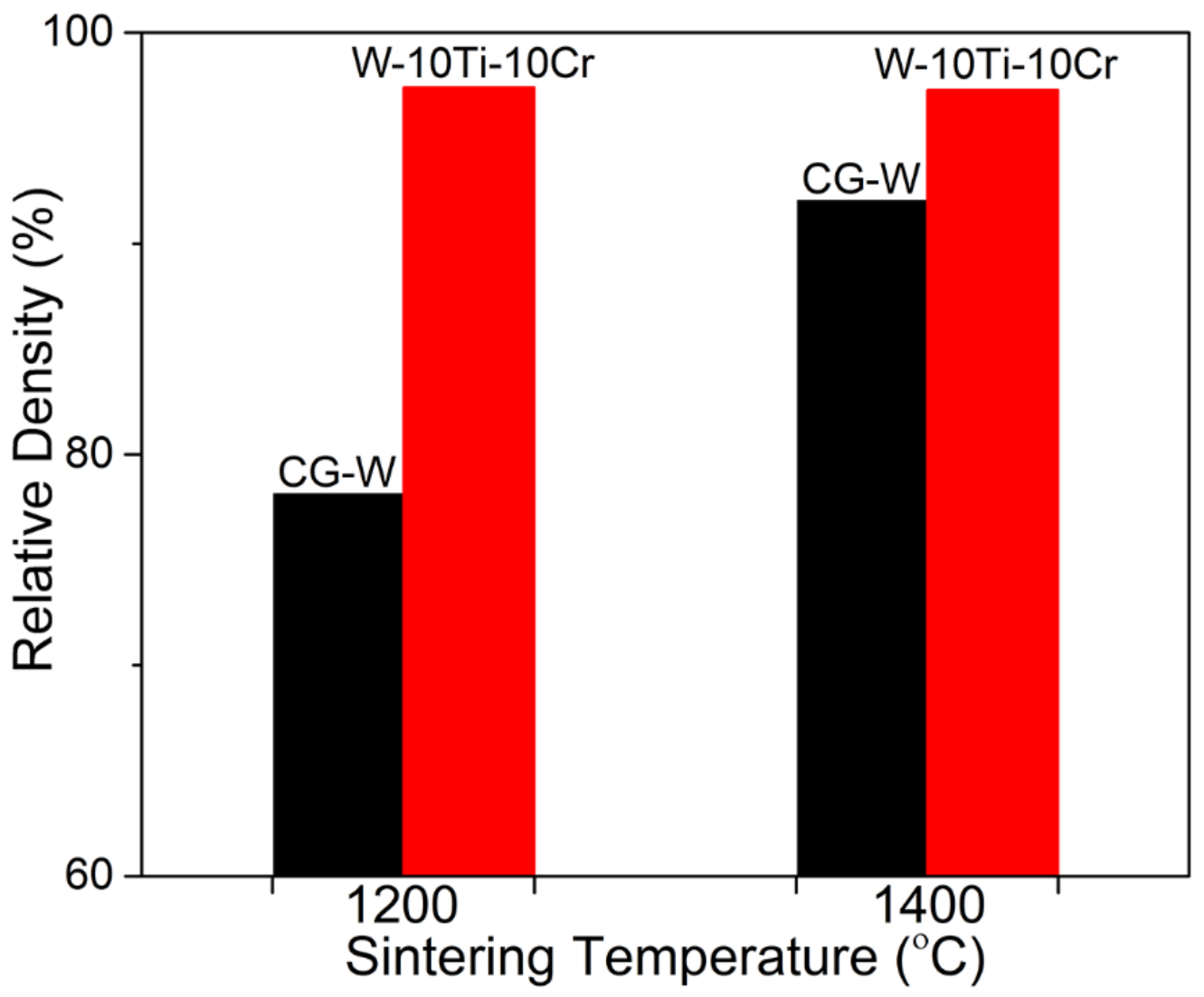

Figure 11. Density of the bulk CG-W and W-10Ti-10Cr alloy for the two isothermal hold temperatures relative to the theoretical value for each sample accounting for the alloy chemistry.

Phase and grain size stability during sintering of the ball-milled W-10Ti-10Cr powders was investigated via synchrotron XRD, selected based on its higher sensitivity to the presence of minor phases and microstructural-based broadening. XRD patterns acquired on the bulk ternary alloy samples sintered with isothermal hold temperatures of $1200{ }^{\circ} \mathrm{C}$ and $1400{ }^{\circ} \mathrm{C}$ are shown in Figure 12. At this scale, both patterns appeared nearly identical and dominated by BCC $\mathrm{W}$ peaks as expected, with additional reflections corresponding to the HCP Ti and FCC TiC phases. However, the $\mathrm{M}_{23} \mathrm{C}_{6}$ phase also precipitated at the 
higher sintering temperature of $1400^{\circ} \mathrm{C}$. The formation of these carbides, as well as its temperature dependence with the $\mathrm{M}_{23} \mathrm{C}_{6}$ phase appearing above $1200{ }^{\circ} \mathrm{C}$ are consistent with the behavior of the annealed $\mathrm{W}-10 \mathrm{Ti}-10 \mathrm{Cr}$ powders. Thus, given the presence of $\mathrm{C}$ impurities in the as-milled powders as discussed in the previous section, we again attribute nanostructure instabilities during sintering to $\mathrm{C}$ impurities driving phase separation of $\mathrm{Ti}$ during the formation of carbides. Interestingly, the fraction of the $\mathrm{TiC}$ phase formed during sintering was markedly enhanced relative to annealing of the powders, which also did not contain any precipitated HCP Ti. The FAST process thus promoted phase separation of Ti along with accelerated formation of $\mathrm{TiC}$ with these two mechanisms likely coupled. The underlying mechanism is related to a combination of the applied compressive force and non-uniform temperature gradients developed in the powder charge and die walls during sintering. However, additional experiments with complementary thermal models of the sintering process are needed to decouple these two effects.
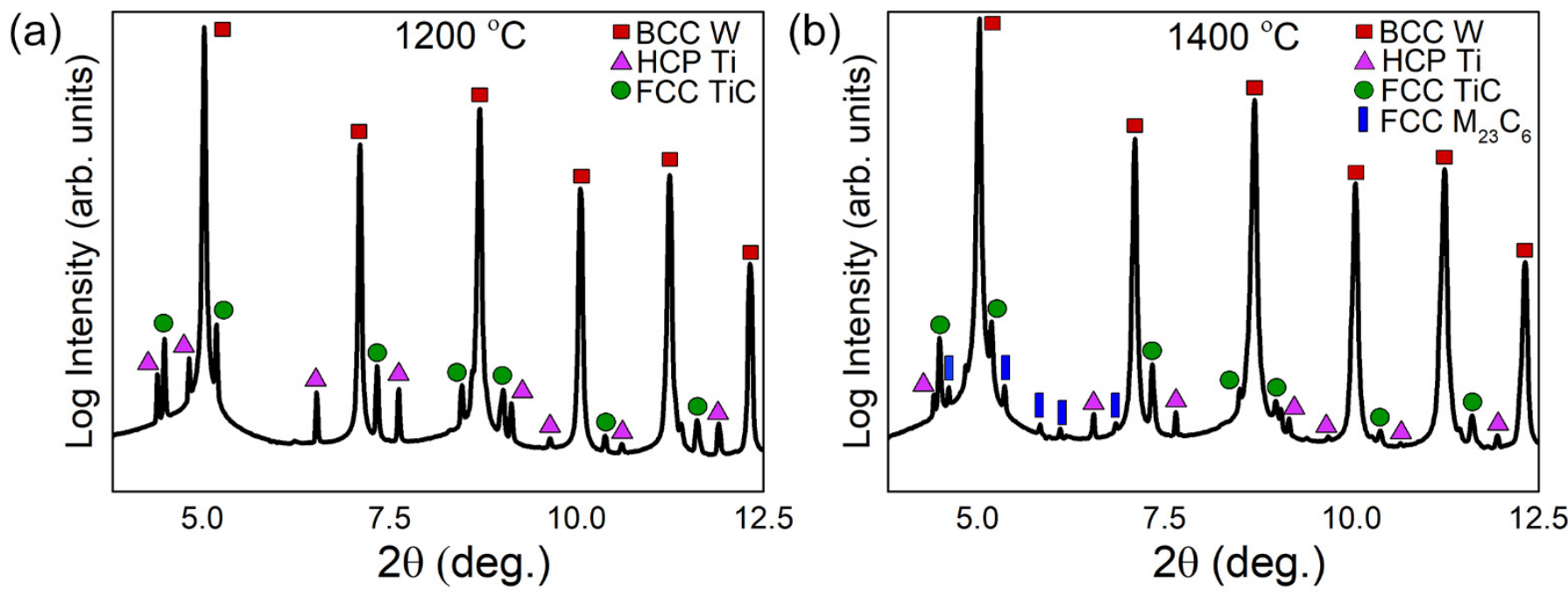

Figure 12. (a) Synchrotron $\mathrm{XRD}$ patterns for the $\mathrm{W}-10 \mathrm{Ti}-10 \mathrm{Cr}$ alloys sintered with isothermal hold temperatures of (a) $1200{ }^{\circ} \mathrm{C}$ and (b) $1400{ }^{\circ} \mathrm{C}$. The primary BCC W peaks as well as the secondary HCP $\mathrm{Ti}$, FCC TiC, and FCC $\mathrm{M}_{23} \mathrm{C}_{6}$ peaks are indexed in each pattern. Distinct crystallographic reflections are deliberately not included alongside each peak for clarity of presentation.

Phase instabilities and the formation of carbides in the bulk alloys were accompanied by a reduction in the degree of peak broadening relative to both the as-milled and annealed powders. Sharper primary BCC W peaks are an indication that grain coarsening transpired during sintering. The resulting mean grain size and phase fractions were quantified through Rietveld refinements that incorporated the HCP Ti, FCC TiC, and FCC $\mathrm{M}_{23} \mathrm{C}_{6}$ phases and shown in Figure 13. The initial grain size of the as-milled W-10Ti-10Cr powder of $15 \mathrm{~nm}$ coarsened significantly during sintering to 270 and $130 \mathrm{~nm}$ at temperatures of $1200{ }^{\circ} \mathrm{C}$ and $1400{ }^{\circ} \mathrm{C}$, respectively. While the former grain size is pushing the limitation of XRD for quantifying grain size (even with the higher sensitivity accessible via synchrotron X-rays), it is clear the nanostructure coarsened to a greater extent at $1200{ }^{\circ} \mathrm{C}$. At first glance, this appears counterintuitive since thermal grain growth occurs more rapidly with increasing temperature. However, with nanostructure stability strongly tied to the distribution of $\mathrm{Ti}$ in a W-rich alloy, precipitating a larger fraction of the HCP Ti at $1200{ }^{\circ} \mathrm{C}$ inevitably competes with the stability of the nanocrystalline grain structure since it draws this solute from the $\mathrm{W}$ matrix and presumably the grain boundaries. Enhanced precipitation of Ti at the intermediate sintering temperature of $1200{ }^{\circ} \mathrm{C}$ is consistent with predictions of nanophase separation in the binary $\mathrm{W}$-Ti system in this temperature range [36]. The nanostructure thus coarsened to a greater extent at this temperature with a smaller grain size favored at the higher temperature of $1400{ }^{\circ} \mathrm{C}$, thus demonstrating stability and retention of a 
fine grain structure through sintering of a W-10Ti-10Cr alloy. Finally, we note that the presence of carbides, particularly $\mathrm{TiC}$, has been shown to improve the radiation tolerance of W [83]; however, the reaction of Ti with $\mathrm{C}$ during sintering is unfavorable since it leads to instabilities. Future efforts will thus be directed to reducing the amount of $\mathrm{C}$ impurities in the milled powders to enhance the retention of the nanocrystalline state in the sintered bulk alloys.

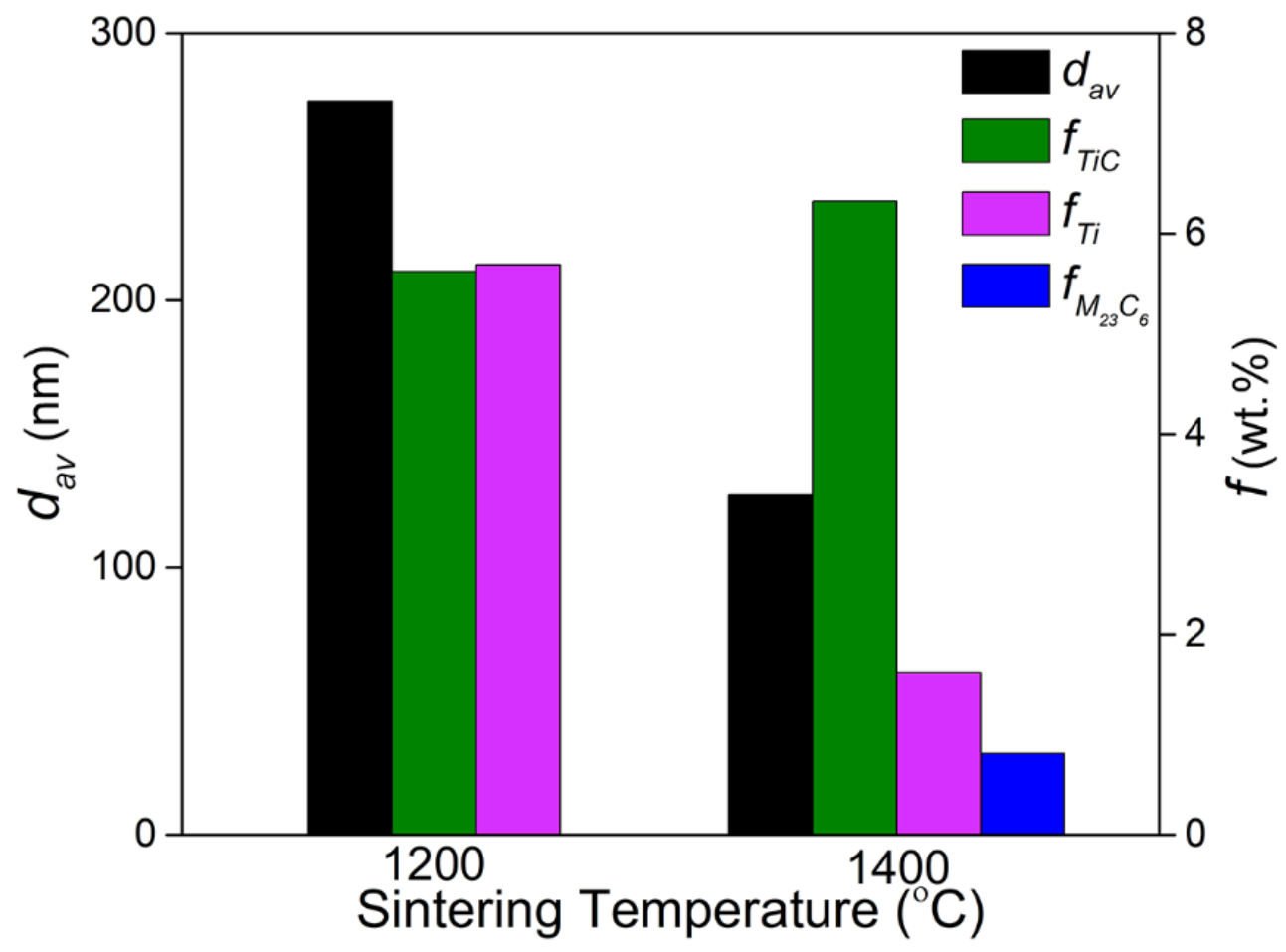

Figure 13. Grain size and phase fractions for the HCP Ti, FCC TiC, and FCC $\mathrm{M}_{23} \mathrm{C}_{6}$ in the bulk $\mathrm{W}-10 \mathrm{Ti}-10 \mathrm{Cr}$ alloys delineated for the two isothermal hold temperatures.

\section{Conclusions}

The evolution of the microstructure in ternary $\mathrm{W}$ alloys containing Ti for suppressing thermal instabilities and $\mathrm{Cr}$ for promoting rapid densification during sintering were mapped during high-energy ball milling. We demonstrated that the milled powders exhibited a bimodal grain size distribution in the nanocrystalline state that combined fine equiaxed nanocrystalline grains with coarser elongated deformed grains, which were retained in the final nanocrystalline powders albeit in low volume fractions. These nanostructures evolved from the coarse grain microstructure of the starting $\mathrm{W}$ powder feedstock via the formation of preferred textures due to the preferred slip systems in BCC W. Specifically, XRD measurements revealed intense (200) peaks at intermediate milling times consistent with the $\{001\}<100>$ orientation $\theta$-fiber texture reported during rolling of $\mathrm{W}$ and other BCC metals. Further grain size refinement was shown to eliminate this texture as deformation shifts away from dislocation plasticity along preferred slip systems toward grain boundary mediated processes. Despite the presence of the bimodal nanocrystalline grain size distribution, the average grain size of $\sim 25 \mathrm{~nm}$ in the milled powders was stable up to $1000{ }^{\circ} \mathrm{C}$ but subsequently coarsened at $1300{ }^{\circ} \mathrm{C}$ to $\sim 60 \mathrm{~nm}$ with a small fraction of distributed carbides. Field-assisted sintering was employed to consolidate the alloy powders into bulk samples, which due to the deliberately designed compositional features, sintered at $\sim 1000{ }^{\circ} \mathrm{C}$ to near total density with ultrafine grain structures retained in the bulk alloy. The small degree of microstructural coarsening during the sintering process is explained in the context of nanophase separation and the formation of minor carbides. Nonetheless, our findings demonstrate the efficacy of the nanocrystalline alloy design 
approach for stabilizing tungsten against recrystallization while enabling powder metallurgical processing of fully dense tungsten alloys with tailored nanostructures for enhancing performance in extreme environments. Future work will focus on: (i) alloy modifications to mitigate the depletion of solute from the grain boundaries due to carbide formation, and (ii) mapping the effect of alloying additions on the thermal properties, which are known to be impacted by alloying in W [84] and represent a critical metric for future PFMs.

Author Contributions: Conceptualization and methodology, J.R.T.; investigation, N.O., B.C., D.J.S. and C.M.P.; resources, J.R.T. and C.M.P.; data curation, N.O. and D.J.S.; formal analysis, N.O., B.C. and D.J.S.; writing—original draft preparation, N.O. and J.R.T.; writing—review and editing, all authors; visualization, N.O. and J.R.T.; supervision, D.J.S. and J.R.T.; project administration, J.R.T.; funding acquisition, J.R.T. and C.M.P. All authors have read and agreed to the published version of the manuscript.

Funding: This work was supported by the U.S. Department of Energy (DOE), Office of Science, Fusion Energy Sciences, under contract DE-SC0017899. Work at ORNL (C.M.P.) was supported by the U.S. DOE, Office of Science, Fusion Energy Sciences, under contract number DE-AC05-00OR22725.

Data Availability Statement: The data presented in this study are available on request from the corresponding author.

Acknowledgments: This research used resources of the Center for Functional Nanomaterials, which is a U.S. DOE Office of Science Facility, at Brookhaven National Laboratory under Contract No. DE-SC0012704. The authors also acknowledge use of beamline 28-ID-2 (XPD) at NSLS-II, a U.S. DOE Office of Science User Facility operated for the DOE Office of Science by Brookhaven National Laboratory under Contract No. DE-SC0012704. The Talos F200X electron microscope was provided by the Nuclear Science User Facilities and the Fuel Cycle Research and Development Program, Office of Nuclear Energy, U.S. DOE.

Conflicts of Interest: The authors declare no conflict of interest. The funders had no role in the design of the study; in the collection, analyses, or interpretation of data; in the writing of the manuscript, or in the decision to publish the results.

\section{References}

1. Chookajorn, T.; Murdoch, H.A.; Schuh, C.A. Design of Stable Nanocrystalline Alloys. Science 2012, 337, 951-954. [CrossRef]

2. Donaldson, O.K.; Hattar, K.; Kaub, T.; Thompson, G.B.; Trelewicz, J.R. Solute stabilization of nanocrystalline tungsten against abnormal grain growth. J. Mater. Res. 2018, 33, 68-80. [CrossRef]

3. Donaldson, O.K.; Wang, W.; Hattar, K.; Trelewicz, J.R. Impurity stabilization of nanocrystalline grains in pulsed laser deposited tantalum. J. Mater. Res. 2017, 32, 1351-1360. [CrossRef]

4. Balbus, G.H.; Kappacher, J.; Sprouster, D.J.; Wang, F.; Shin, J.; Eggeler, Y.M.; Rupert, T.J.; Trelewicz, J.R.; Kiener, D.; Maier-Kiener, V.; et al. Disordered Interfaces Enable High Temperature Thermal Stability and Strength in a Nanocrystalline Aluminum Alloy. Acta Mater. 2021, 116973. [CrossRef]

5. Pun, S.C.; Wang, W.; Khalajhedayati, A.; Schuler, J.D.; Trelewicz, J.R.; Rupert, T.J. Nanocrystalline Al-Mg with extreme strength due to grain boundary doping. Mater. Sci. Eng. A 2017, 696, 400-406. [CrossRef]

6. Zhang, Y.; Tucker, G.J.; Trelewicz, J.R. Stress-assisted grain growth in nanocrystalline metals: Grain boundary mediated mechanisms and stabilization through alloying. Acta Mater. 2017, 131, 39-47. [CrossRef]

7. Tang, F.; Gianola, D.S.; Moody, M.P.; Hemker, K.J.; Cairney, J.M. Observations of grain boundary impurities in nanocrystalline Al and their influence on microstructural stability and mechanical behaviour. Acta Mater. 2012, 60, 1038-1047. [CrossRef]

8. Frolov, T.; Darling, K.A.; Kecskes, L.J.; Mishin, Y. Stabilization and strengthening of nanocrystalline copper by alloying with tantalum. Acta Mater. 2012, 60, 2158-2168. [CrossRef]

9. Cunningham, W.S.; Hattar, K.; Zhu, Y.; Edwards, D.J.; Trelewicz, J.R. Suppressing irradiation induced grain growth and defect accumulation in nanocrystalline tungsten through grain boundary doping. Acta Mater. 2021, 206, 116629. [CrossRef]

10. Beyerlein, I.J.; Caro, A.; Demkowicz, M.J.; Mara, N.A.; Misra, A.; Uberuaga, B.P. Radiation damage tolerant nanomaterials. Mater. Today 2013, 16, 443-449. [CrossRef]

11. Han, W.Z.; Demkowicz, M.J.; Mara, N.A.; Fu, E.G.; Sinha, S.; Rollett, A.D.; Wang, Y.Q.; Carpenter, J.S.; Beyerlein, I.J.; Misra, A. Design of Radiation Tolerant Materials Via Interface Engineering. Adv. Mater. 2013, 25, 6975-6979. [CrossRef] [PubMed]

12. Perrin, A.E.; Schuh, C.A. Stabilized Nanocrystalline Alloys: The Intersection of Grain Boundary Segregation with Processing Science. Ann. Rev. Mater. Res. 2021, 51. [CrossRef]

13. Suryanarayana, C. Mechanical alloying and milling. Progress Mater. Sci. 2001, 46, 1-184. [CrossRef]

14. Suryanarayana, C. Non-equilibrium Processing of Materials; Elsevier: Oxford, UK, 1999. 
15. Han, Y.; Fan, J.; Liu, T.; Cheng, H.; Tian, J. The effects of ball-milling treatment on the densification behavior of ultra-fine tungsten powder. Int. J. Refract. Met. Hard Mater. 2011, 29, 743-750. [CrossRef]

16. Wu, Z.M.; Liang, Y.X.; Fan, Y.; Wang, P.P.; Du, J.L.; Zhao, Y.B.; Fu, E.G. The ball to powder ratio (BPR) dependent morphology and microstructure of tungsten powder refined by ball milling. Powder Technol. 2018, 339, 256-263. [CrossRef]

17. Liang, Y.X.; Wu, Z.M.; Fu, E.G.; Du, J.L.; Wang, P.P.; Zhao, Y.B.; Qiu, Y.H.; Hu, Z.Y. Refinement process and mechanisms of tungsten powder by high energy ball milling. Int. J. Refract. Met. Hard Mater. 2017, 67, 1-8. [CrossRef]

18. Wu, Z.; Liang, Y.; Fu, E.; Du, J.; Wang, P.; Fan, Y.; Zhao, Y. Effect of Ball Milling Parameters on the Refinement of Tungsten Powder. Metals 2018, 8, 281. [CrossRef]

19. Korchagin, M.A.; Ditenberg, I.A.; Denisov, K.I.; Tyumentsev, A.N. Microstructure and properties of pure and composite metal powders after mechanical activation in planetary ball mill. AIP Conf. Proc. 2014, 1623, 291-294.

20. Ueda, Y.; Coenen, J.W.; De Temmerman, G.; Doerner, R.P.; Linke, J.; Philipps, V.; Tsitrone, E. Research status and issues of tungsten plasma facing materials for ITER and beyond. Fusion Eng. Des. 2014, 89, 901-906. [CrossRef]

21. Uytdenhouwen, I.; Decreton, M.; Hirai, T.; Linke, J.; Pintsuk, G.; Van Oost, G. Influence of recrystallization on thermal shock resistance of various tungsten grades. J. Nucl. Mater. 2007, 363, 1099-1103. [CrossRef]

22. Loewenhoff, T.; Bürger, A.; Linke, J.; Pintsuk, G.; Schmidt, A.; Singheiser, L.; Thomser, C. Evolution of tungsten degradation under combined high cycle edge-localized mode and steady-state heat loads. Phys. Scr. 2011, T145, 014057. [CrossRef]

23. Hu, X.X.; Koyanagi, T.; Fukuda, M.; Kumar, N.; Snead, L.L.; Wirth, B.D.; Katoh, Y. Irradiation hardening of pure tungsten exposed to neutron irradiation. J. Nucl. Mater. 2016, 480, 235-243. [CrossRef]

24. Coenen, J.W.; Mao, Y.; Almanstötter, J.; Calvo, A.; Sistla, S.; Gietl, H.; Jasper, B.; Riesch, J.; Rieth, M.; Pintsuk, G.; et al. Advanced materials for a damage resilient divertor concept for DEMO: Powder-metallurgical tungsten-fibre reinforced tungsten. Fusion Eng. Des. 2017, 124, 964-968. [CrossRef]

25. Wu, Z.M.; Zhang, J.; Zhang, J.; Huang, J.C.; Fan, Y.; Yu, X.H.; Zhao, Y.B.; Zhu, J.L.; Jin, C.Q.; Wang, P.; et al. Nanocrystalline W-based alloys with ultrahigh hardness and exceptional irradiation tolerance. Nuclear Fusion 2019, 59, 106050. [CrossRef]

26. Litnovsky, A.; Wegener, T.; Klein, F.; Linsmeier, C.; Rasinski, M.; Kreter, A.; Tan, X.; Schmitz, J.; Coenen, J.W.; Mao, Y.; et al. New oxidation-resistant tungsten alloys for use in the nuclear fusion reactors. Phys. Scr. 2017, T170, 014012. [CrossRef]

27. El-Atwani, O.; Li, N.; Li, M.; Devaraj, A.; Baldwin, J.K.S.; Schneider, M.M.; Sobieraj, D.; Wróbel, J.S.; Nguyen-Manh, D.; Maloy, S.A.; et al. Outstanding radiation resistance of tungsten-based high-entropy alloys. Sci. Adv. 2019, 5, eaav2002. [CrossRef]

28. Wurster, S.; Baluc, N.; Battabyal, M.; Crosby, T.; Du, J.; García-Rosales, C.; Hasegawa, A.; Hoffmann, A.; Kimura, A.; Kurishita, H.; et al. Recent progress in R\&D on tungsten alloys for divertor structural and plasma facing materials. J. Nucl. Mater. 2013, 442, S181-S189. [CrossRef]

29. Wei, Q.; Jiao, T.; Ramesh, K.T.; Ma, E.; Kecskes, L.J.; Magness, L.; Dowding, R.; Kazykhanov, V.U.; Valiev, R.Z. Mechanical behavior and dynamic failure of high-strength ultrafine grained tungsten under uniaxial compression. Acta Mater. 2006, 54, 77-87. [CrossRef]

30. Zhang, Y.; Ganeev, A.V.; Wang, J.T.; Liu, J.Q.; Alexandrov, I.V. Observations on the ductile-to-brittle transition in ultrafine-grained tungsten of commercial purity. Mater. Sci. Eng. A 2009, 503, 37-40. [CrossRef]

31. Hao, T.; Fan, Z.Q.; Zhang, T.; Luo, G.N.; Wang, X.P.; Liu, C.S.; Fang, Q.F. Strength and ductility improvement of ultrafine-grained tungsten produced by equal-channel angular pressing. J. Nucl. Mater. 2014, 455, 595-599. [CrossRef]

32. Weissmuller, J. Alloy effects in nanostructures. Nanostructured Mater. 1993, 3, 261-272. [CrossRef]

33. Trelewicz, J.R.; Schuh, C.A. Grain boundary segregation and thermodynamically stable binary nanocrystalline alloys. Phys. Rev. B 2009, 79, 094112. [CrossRef]

34. Liu, F.; Kirchheim, R. Nano-scale grain growth inhibited by reducing grain boundary energy through solute segregation. J. Cryst. Growth 2004, 264, 385-391. [CrossRef]

35. Murdoch, H.A.; Schuh, C.A. Stability of binary nanocrystalline alloys against grain growth and phase separation. Acta Mater. 2013, 61, 2121-2132. [CrossRef]

36. Chookajorn, T.; Schuh, C.A. Nanoscale segregation behavior and high-temperature stability of nanocrystalline W-20 at.\% Ti. Acta Mater. 2014, 73, 128-138. [CrossRef]

37. Senthilnathan, N.; Raja Annamalai, A.; Venkatachalam, G. Activated sintering of tungsten alloys through conventional and spark plasma sintering process. Mater. Manuf. Processes 2017, 32, 1861-1868. [CrossRef]

38. Ren, C.; Fang, Z.Z.; Zhang, H.; Koopman, M. The study on low temperature sintering of nano-tungsten powders. Int. J. Refract. Met. Hard Mater. 2016, 61, 273-278. [CrossRef]

39. Brandon, M.; Antonios, Z.; Cho, K.C.; Dowding, R.J. The Modeling of Electric-CurrentAssisted Sintering to Produce Bulk Nanocrystalline Tungsten. J. Miner. Met. Mater. Soc. 2006, 58, 67-71.

40. Orrù, R.; Licheri, R.; Locci, A.M.; Cincotti, A.; Cao, G. Consolidation/synthesis of materials by electric current activated/assisted sintering. Mater. Sci. Eng. R Rep. 2009, 63, 127-287. [CrossRef]

41. Choi, J.; Sung, H.-M.; Roh, K.-B.; Hong, S.-H.; Kim, G.-H.; Han, H.N. Fabrication of sintered tungsten by spark plasma sintering and investigation of thermal stability. Int. J. Refract. Met. Hard Mater. 2017, 69, 164-169. [CrossRef]

42. Lee, G.; McKittrick, J.; Ivanov, E.; Olevsky, E.A. Densification mechanism and mechanical properties of tungsten powder consolidated by spark plasma sintering. Int. J. Refract. Met. Hard Mater. 2016, 61, 22-29. [CrossRef] 
43. Jacobs, J.; Haque, A.; Kulkarni, A.; Singh, J.; Matson, L. Microstructure of tungsten metal alloys produced by Field Assisted Sintering Technology (FAST). Int. J. Refract. Met. Hard Mater. 2019, 84, 104976. [CrossRef]

44. Chanthapan, S.; Kulkarni, A.; Singh, J.; Haines, C.; Kapoor, D. Sintering of tungsten powder with and without tungsten carbide additive by field assisted sintering technology. Int. J. Refract. Met. Hard Mater. 2012, 31, 114-120. [CrossRef]

45. Nygren, R.E.; Raffray, R.; Whyte, D.; Urickson, M.A.; Baldwin, M.; Snead, L.L. Making tungsten work-ICFRM-14 session T26 paper 501 Nygren et al. making tungsten work. J. Nucl. Mater. 2011, 417, 451-456. [CrossRef]

46. Tsuchida, K.; Miyazawa, T.; Hasegawa, A.; Nogami, S.; Fukuda, M. Recrystallization behavior of hot-rolled pure tungsten and its alloy plates during high-temperature annealing. Nuclear Mater. Energy 2018, 15, 158-163. [CrossRef]

47. Alfonso, A.; Juul Jensen, D.; Luo, G.N.; Pantleon, W. Recrystallization kinetics of warm-rolled tungsten in the temperature range 1150-1350 ${ }^{\circ}$ C. J. Nucl. Mater. 2014, 455, 591-594. [CrossRef]

48. Philipps, V. Tungsten as material for plasma-facing components in fusion devices. J. Nucl. Mater. 2011, 415, S2-S9. [CrossRef]

49. Pramanik, S.; Srivastav, A.K.; Manuel Jolly, B.; Chawake, N.; Murty, B.S. Effect of Re on microstructural evolution and densification kinetics during spark plasma sintering of nanocrystalline W. Adv. Powder Technol. 2019, 30, 2779-2786. [CrossRef]

50. Ding, L.; Xiang, D.P.; Li, Y.Y.; Li, C.; Li, J.B. Effects of sintering temperature on fine-grained tungsten heavy alloy produced by high-energy ball milling assisted spark plasma sintering. Int. J. Refract. Met. Hard Mater. 2012, 33, 65-69. [CrossRef]

51. Yao, M.; Zhangjian, Z.; Jun, T.; Ming, L. Fabrication of Ultra-fine Grain Tungsten by Combining Spark Plasma Sintering with Resistance Sintering under Ultra High Pressure. Rare Met. Mater. Eng. 2011, 40, 4-8. [CrossRef]

52. El-Atwani, O.; Quach, D.V.; Efe, M.; Cantwell, P.R.; Heim, B.; Schultz, B.; Stach, E.A.; Groza, J.R.; Allain, J.P. Multimodal grain size distribution and high hardness in fine grained tungsten fabricated by spark plasma sintering. Mater. Sci. Eng. A 2011, 528, 5670-5677. [CrossRef]

53. Park, M.; Schuh, C.A. Accelerated sintering in phase-separating nanostructured alloys. Nat. Commun. 2015, 6, 6858. [CrossRef] [PubMed]

54. Chookajorn, T.; Park, M.; Schuh, C.A. Duplex nanocrystalline alloys: Entropic nanostructure stabilization and a case study on W-Cr. J. Mater. Res. 2015, 30, 151-163. [CrossRef]

55. Xing, W.; Kalidindi, A.R.; Schuh, C.A. Preferred nanocrystalline configurations in ternary and multicomponent alloys. Scr. Mater. 2017, 127, 136-140. [CrossRef]

56. Kireš, M. Archimedes' principle in action. Phys. Educ. 2007, 42, 484-487. [CrossRef]

57. Shi, X.; Ghose, S.; Dooryhee, E. Performance calculations of the X-ray powder diffraction beamline at NSLS-II. J. Synchrotron. Radiat. 2013, 20, 234-242. [CrossRef] [PubMed]

58. Lutterotti, L.; Matthies, S.; Wenk, H.R.; Schultz, A.S.; Richardson, J.W. Combined texture and structure analysis of deformed limestone from time-of-flight neutron diffraction spectra. J. Appl. Phys. 1997, 81, 594-600. [CrossRef]

59. Ungar, T. Micro structural parameters from X-ray diffraction peak broadening. Scr. Mater. 2004, 51, 777-781. [CrossRef]

60. Williamson, G.K.; Hall, W.H. X-ray line broadening from filed aluminium and wolfram. Acta Metall. 1953, 1, 22-31. [CrossRef]

61. Srinivasarao, B.; Oh-ishi, K.; Ohkubo, T.; Hono, K. Bimodally grained high-strength Fe fabricated by mechanical alloying and spark plasma sintering. Acta Mater. 2009, 57, 3277-3286. [CrossRef]

62. Schwarzer, R. The Determination of Local Texture by Electron Diffraction-A Tutorial Review. Texture Microstruct. 1993, 20 . [CrossRef]

63. Oda, E.; Fujiwara, H.; Ameyama, K. Nano Grain Formation in Tungsten by Severe Plastic Deformation-Mechanical Milling Process. Mater. Trans. 2008, 49, 54-57. [CrossRef]

64. Sarkar, R.; Ghosal, P.; Premkumar, M.; Singh, A.K.; Muraleedharan, K.; Chakraborti, A.; Bagchi, T.P.; Sarma, B. Characterisation and sintering studies of mechanically milled nano tungsten powder. Powder Metall. 2013, 51, 166-170. [CrossRef]

65. Oda, E.; Ameyama, K.; Yamaguchi, S. Fabrication of Nano Grain Tungsten Compact by Mechanical Milling Process and Its High Temperature Properties. Mater. Sci. Forum 2006, 503-504, 573-578. [CrossRef]

66. Fujiwara, H.; Oda, E.; Ameyama, K. Mechanical Milling Process as Severe Plastic Deformation Method. Tetsu Hagane 2008, 94 , 608-615. [CrossRef]

67. Marichal, C.; Van Swygenhoven, H.; Van Petegem, S.; Borca, C. $\{110\}$ Slip with $\{112\}$ slip traces in bcc Tungsten. Sci. Rep. 2013, 3, 2547. [CrossRef]

68. Hull, D.; Byron, J.F.; Noble, F.W. Orientation Dependence of Yield in Body-Centered Cubic Metals. Can. J. Phys. 1967, 45, 1091-1099. [CrossRef]

69. Christian, J.W. Some surprising features of the plastic deformation of body-centered cubic metals and alloys. Metall. Trans. A 1983, 14, 1237-1256. [CrossRef]

70. Bingert, J.; Desch, P.; Bingert, S.; Maudlin, P.; Tome, C. Texture Evolution in Upset-Forged P/M and Wrought Tantalum: Experimentation and Modeling; Los Alamos National Laboratory: Los Alamos, NM, USA, 1997.

71. Jang, D.; Atzmon, M. Grain-size dependence of plastic deformation in nanocrystalline Fe. J. Appl. Phys. 2003, 93, 9282-9286. [CrossRef]

72. Wyckoff, R.W.G. Crystal Structures; Interscience Publishers: New York, NY, USA, 1963.

73. Kestens, L.A.I.; Pirgazi, H. Texture formation in metal alloys with cubic crystal structures. Mater. Sci. Technol. 2016, 32, 1303-1315. [CrossRef] 
74. Raabe, D. Simulation of rolling textures of b.c.c. metals considering grain interactions and crystallographic slip on $\{110\},\{112\}$ and $\{123\}$ planes. Mater. Sci. Eng. A 1995, 197, 31-37. [CrossRef]

75. Lied, P.; Bonnekoh, C.; Pantleon, W.; Stricker, M.; Hoffmann, A.; Reiser, J. Comparison of K-doped and pure cold-rolled tungsten sheets: As-rolled condition and recrystallization behaviour after isochronal annealing at different temperatures. Int. J. Refract. Met. Hard Mater. 2019, 85, 105047. [CrossRef]

76. Wang, S.; Wu, Z.H.; Xie, M.Y.; Si, D.H.; Li, L.Y.; Chen, C.; Zhang, Z.; Wu, Y.C. The effect of tungsten content on the rolling texture and microstructure of Ta-W alloys. Mater. Charact. 2020, 159, 110067. [CrossRef]

77. Raabe, D.; Lücke, K. Rolling and Annealing Textures of BCC Metals. Mater. Sci. Forum 1994, 157-162, 597-610. [CrossRef]

78. Zhang, X.; Yan, Q.; Lang, S.; Xia, M.; Ge, C. Texture evolution and basic thermal-mechanical properties of pure tungsten under various rolling reductions. J. Nucl. Mater. 2016, 468, 339-347. [CrossRef]

79. Deng, C.; Liu, S.F.; Ji, J.L.; Hao, X.B.; Zhang, Z.Q.; Liu, Q. Texture evolution of high purity tantalum under different rolling paths. J. Mater. Processing Technol. 2014, 214, 462-469. [CrossRef]

80. Bonk, S.; Reiser, J.; Hoffmann, J.; Hoffmann, A. Cold rolled tungsten (W) plates and foils: Evolution of the microstructure. Int. J. Refract. Met. Hard Mater. 2016, 60, 92-98. [CrossRef]

81. Naidu, S.V.N.; Sriramamurthy, A.M.; Rao, P.R. The Cr-W (Chromium-Tungsten) system. Bull. Alloy Phase Diagr. 1984, 5, 289. [CrossRef]

82. Gilbert, M.R.; Arakawa, K.; Bergstrom, Z.; Caturla, M.J.; Dudarev, S.L.; Gao, F.; Goryaeva, A.M.; Hu, S.Y.; Hu, X.; Kurtz, R.J.; et al. Perspectives on multiscale modelling and experiments to accelerate materials development for fusion. J. Nucl. Mater. 2021, 554, 153113. [CrossRef]

83. El-Atwani, O.; Cunningham, W.S.; Esquivel, E.; Li, M.; Trelewicz, J.R.; Uberuaga, B.P.; Maloy, S.A. In-situ irradiation tolerance investigation of high strength ultrafine tungsten-titanium carbide alloy. Acta Mater. 2019, 164, 547-559. [CrossRef]

84. Vilémová, M.; Illková, K.; Lukáč, F.; Matějíček, J.; Klečka, J.; Leitner, J. Microstructure and phase stability of W-Cr alloy prepared by spark plasma sintering. Fusion Eng. Des. 2018, 127, 173-178. [CrossRef] 